April 2005

\title{
Technology Matters: The Courts, Media Neutrality, and New Technologies
}

Deborah Tussey

Oklahoma City University School of Law

Follow this and additional works at: https://digitalcommons.law.uga.edu/jipl

Part of the Game Design Commons, and the Intellectual Property Law Commons

\section{Recommended Citation}

Deborah Tussey, Technology Matters: The Courts, Media Neutrality, and New Technologies, 12 J. INTELL. PROP. L. 427 (2005).

Available at: https://digitalcommons.law.uga.edu/jipl/vol12/iss2/3

This Article is brought to you for free and open access by Digital Commons @ University of Georgia School of Law. It has been accepted for inclusion in Journal of Intellectual Property Law by an authorized editor of Digital Commons @ University of Georgia School of Law. Please share how you have benefited from this access For more information, please contact tstriepe@uga.edu. 


\section{TECHNOLOGY MATTERS: THE COURTS, MEDIA NEUTRALITY, AND NEW TECHNOLOGIES}

\section{Deborab Tussey* \\ I. INTRODUCTION}

During the past two centuries, copyright law has adapted, though not always quickly or easily, to the development and popularization of new technologies as diverse as player pianos, photography, television, radio, and photocopiers. Electronic media pose the most serious challenge thus far to copyright's most basic concepts, down to and including even the definition of an actionable copy. Congress has responded to technological change by extending copyright protection to new subject matters and media ${ }^{1}$ and, most recently, by blessing copyright protection technologies. ${ }^{2}$ Courts applying the copyright statutes, however, often face the difficult task of applying generalized legislative language to the particular workings of technologies not fully anticipated by Congress.

In Wbite-Smith Publisbing Co. v. Apollo Co., the Supreme Court applied copyright law to the then-new and rapidly growing technology of player pianos and piano rolls. ${ }^{3}$ Rejecting the argument that Congress meant to protect copyrighted musical works against infringement by any means of expression which embodied the composer's work, the Court found that piano rolls did not infringe composers' copyrights because piano rolls were not human-readable copies of the compositions, like sheet music, but merely devices which operated player pianos.

The Copyright Act, the Court said,

has not provided for the protection of the intellectual conception apart from the thing produced, however meritorious such conception may be, but has provided for the making and filing of a

* Associate Professor, Oklahoma City University School of Law. Thanks to Sam Lupica and to participants in the OCU Faculty Colloquium and the 2003 Works-in-Progress IP Colloquium at Tulane for their comments on earlier drafts of this Article. The writing of this Article was supported by a grant from the Kerr Foundation and Law Alumni Fund.

1 I. Trotter Hardy, Copyright and New Use Technologies, 23 NovA L. REV. 659, 663-66 (1999).

2 See Digital Millennium Copyright Act; Pub. L. No. 105-304, 112 Stat. 2860 (codified as amended in scattered sections of 17 U.S.C.) (prohibiting circumvention of technological measures protecting copyrighted works).

${ }^{3} 209$ U.S. 1 (1908). Piano rolls are perforated paper cylinders which serve as templates directing player pianos to perform popular musical works. 
tangible thing, against the publication and duplication of which it is the purpose of the statute to protect the composer. ${ }^{4}$

Courts may yet cite White-Smith favorably for its reluctance to expand copyright protection too readily to new technologies, ${ }^{5}$ but Congress stepped in to correct its narrow, technical interpretation of the copyright statute by adopting the principle of media neutrality.

Media neutrality, in general terms, means that the copyright owner's rights should be the same regardless of the form, whether analog or digital, in which the work may be embodied or fixed. Congress adopted broad statutory language including within copyright's ambit all existing and later developed media through which works could be communicated either directly or with the aid of a device. ${ }^{6}$ It intended to provide courts with much-needed flexibility to re-interpret existing copyright law in light of new technologies, authorizing the judiciary to expand copyright as necessary to meet the challenges posed by, in particular, new electronic technologies. ${ }^{7}$ While courts have only rarely discussed the principle of media neutrality at length, they have certainly taken an active role in applying often minimalist statutory directives to electronic works, notably by developing a body of law fleshing out the contours of copyright protection for software. ${ }^{8}$

In several recent cases, however, courts addressing copyright claims involving electronic information storage and retrieval systems have relied heavily on functional characteristics of the systems in crafting judgments that construe key concepts of copyright law. These cases illustrate technology-centered, as opposed to media neutral, analyses and demonstrate a certain tension between the principle of media-neutrality and the countervailing judicial reluctance to venture too far into the field of policymaking without legislative guidance.

While that reluctance was historically prevalent in formalistic judgments like that rendered in White-Smith, the Supreme Court reformulated it in policy-based

${ }^{4}$ Id. at 17.

5 See, e.g., Sony Corp. of Am. v. Universal City Studios, 464 U.S. 417, 430 n.11, 220 U.S.P.Q. (BNA) 665, 673 (1984).

'See 17 U.S.C. $\$ 101$ (2002) (defining the term "copy").

7 Congress first responded to White-Smith in the 1909 Copyright Act by establishing a compulsory license for recordings of musical works. See 17 U.S.C. $\$ 115$ (2000) for the current provision. In the 1976 Copyright Act, Congress more explicitly overruled White-Smith by establishing the principle of media neutrality in 17 U.S.C. $\$ 101,102$ (2000). See Hardy, supra note 1, at 673-78; see also infra Part II.A.

8 See, e.g., Computer Assoc. Int'l, Inc. v. Altai, Inc., 982 F.2d 693 (2d Cir. 1992) (reinterpreting the traditional copyright infringement analysis in the context of nonliteral copying of software); Apple Computer, Inc. v. Franklin Computer Corp., 714 F.2d 1240, 219 U.S.P.Q. (BNA) 113 (3d Cir. 1983) (establishing copyright protection for operating system software as embodied in source, code, object code, and ROM chips). 
terms in its influential decision in the Sony case.' The Court suggested a cautious approach where judicial extension of copyright protection could adversely impact innovation in unrelated technology markets by, in effect, giving copyright owners veto power over the dissemination of new, potentially useful technologies. A superficial reading of the media neutrality principle coupled with Sony's staple article of commerce doctrine calls to mind a game of "hot potato" in which Congress and the Court each attempt to pass off responsibility for the troublesome issue of technological adaptation. ${ }^{10}$ I suggest, however, that media neutrality and the staple article of commerce doctrine can profitably be read together to produce an informed, balanced judicial approach to new technologies which recognizes, but does not unduly rely on, technological distinctions among delivery systems.

In Part II of this Article, I propose a broad reading of the media neutrality principle and explore the difficulty in digital environments of drawing clear borders among the intangible work, its tangible embodiments, and the electronic infrastructure translating between the two. I then outline the staple article of commerce doctrine and suggest that it be read in conjunction with media neutrality to produce a policy-informed, empirically-based judicial approach to new technologies. In Part III, I review three sets of cases dealing with videogame enhancements, database compilations, and peer-to-peer music sharing. Each set is a cycle in which two or more courts faced similar issues. In each set of cases, at least one court employs a White-Smith-like focus on technological detail and definitional readings of statutory language or established copyright concepts. In these cases, technology matters more than it should in a media neutral regime, with the result that the varying fortunes of the parties depend on the precise architecture of certain electronic storage and retrieval systems as viewed through the lens of copyright doctrines defining reproduction, distribution, adaptation, and secondary infringement liability. Part IV explores in greater depth common issues raised by these cases, including flaws in the courts' analytical approach to technology-intensive cases, related concerns about the level of the courts' understanding of the technologies, and apparent disadvantages of technologydriven decisionmaking. In Part V, I suggest that a narrow focus on particular technologies contravenes the principle of media neutrality. I propose a more balanced judicial analysis, that, insofar as possible, accords like legal treatment to functional equivalents, giving greater weight to established copyright principles and to policies concerning fairness, incentives, and innovation than to technologi-

9 Sony, 464 U.S. at 417.

${ }^{10}$ See id. The staple article of commerce doctrine immunizes providers of technologies with substantial noninfringing where consumers also use the technology for infringement. See infra Part II.C. 
cal specifics. Technological variations would matter under this approach, particularly with respect to determinations of equivalency and secondary liability, but should not, standing alone, be outcome determinative.

In this Article, I do not intend to offer a comprehensive review of judicial treatments of electronic technology; however, I do intend to point out, in several discrete contexts, the difficulties caused where courts concentrate too closely on technological trees without due regard to the broader view of the forest. The technology-centered decisions may be modern White-Smiths pursuing definitional minutiae while paying insufficient attention to broader policy concerns.

\section{The BASICS: MEdia NeUtrality, ELECTRONIC MEDiA, AND SONY}

This part discusses the provenance of the principle of media neutrality and particular difficulties that electronic media may pose for media-neutral interpretation of copyright law. I propose a broad interpretation of the principle to require that, where statutory guidance is lacking or ambiguous, courts faced with new systems for storing, retrieving, and transmitting copyrighted content should apply copyright law in a technology-neutral manner. Media neutrality, so construed, confers fairly broad authority on courts to extend protection to copyrighted content distributed through new technologies. I suggest, however, that judicial concerns about the relative institutional competencies of Congress and the courts, most clearly expressed in the Sony decision, impose limitations on the courts' authority to expand copyright protection where important countervailing policies are in play.

\section{A. MEDIA NEUTRALITY AND THE FIXATION REQUIREMENT}

The 1976 Copyright Act reinforced the traditional distinction between the intangible work and its tangible embodiments. The distinction now marks the boundary between the copyright owner's statutory rights in the intangible work ${ }^{11}$ and the rights of a lawful copy owner in the physical copy under the first sale doctrine, which cuts off the copyright owner's right to control particular copies once they have been sold. ${ }^{12}$

11 The copyright owner possesses a statutorily-defined bundle of rights that includes the right to reproduce the work in copies or phonorecords, the right to prepare derivative works, the right to distribute the work in copies or phonorecords, and the rights to publicly perform and display works, including the right to publicly perform sound recordings by digital audio transmission. See 17 U.S.C. $\$ 106(2000)$. Additionally, as will be seen in the database cases, compilers of collective works possess a revision privilege. See 17 U.S.C. $\$ 201$ (c) (2000).

12 The first sale doctrine originally derived from the common law prohibition of restraints on alienation of chattels and is now codified as 17 U.S.C. $\$ 109$ (a) (2000). See H.R. REP. NO. 98-987, 
Congress established the legal line between the work and the copy through its formulation of the fixation requirement. Fixation in a tangible medium of expression-that is embodiment in material form in a copy or phonorecord-is the defining act that brings an intangible work within the protection of federal copyright law. ${ }^{13}$ Fixation is also required to establish infringement of the reproduction and distribution rights $;{ }^{14}$ as a practical matter, the real scope of copyright protection is often established in infringement actions. In order to assure that copyright law remained media neutral, Congress defined fixation of works to include "any tangible medium of expression, now known or later developed, from which they can be perceived, reproduced, or otherwise communicated, either directly or with the aid of a machine or device."15

As noted in the legislative history:

This broad language is intended to avoid the artificial and largely unjustifiable distinctions, derived from cases such as [WhiteSmitb] ... under which statutory copyrightability in certain cases has been made to depend upon the form or medium in which the work is fixed. Under the bill it makes no difference what the form, manner, or medium of fixation may be-whether it is in words, numbers, notes, sounds, pictures, or any other graphic or symbolic indicia, whether embodied in a physical object in written, printed, photographic, sculptural, punched, magnetic, or any other stable form, and whether it is capable of perception directly or by means of any machine or device 'now known or later developed."16

at 2 (1984). The distinction between works and copies is of particular importance in limiting the scope of the derivative works right. See Amy B. Cohen, When Does $A$ Work Infringe the Derivative Works Right of a Copyright Owner?, 17 CARDOZO ARTS \& ENT. LJ. 623, 629-33 (1999) (discussing the historical development of, and inherent tension between, the first sale doctrine and the derivative works right).

${ }^{13}$ See 17 U.S.C. $\$ 102$ (a) (2000). A work is deemed to be "created" when it is first fixed in a copy or phonorecord. 17 U.S.C. $\$ 101(2000)$. Unfixed works may still receive protection under state common law copyright, but are not protected under the federal act.

${ }^{14}$ The reproduction and distribution rights of the copyright holder are specifically limited to copies and phonorecords, which are defined as material objects in which works are fixed. 17 U.S.C. ff 101,106 (2004). Whether fixation is a prerequisite for infringement of the derivative works rights is an unsettled question. See infra Part III.A.

1517 U.S.C. $\$ 102(a)$.

${ }^{16}$ H.R. REP. 94-1476, at 5665 (1976). 
Media neutrality language also appears in a series of key statutory definitions, ${ }^{17}$ though such language is noticeably absent from the definitions of derivative works and compilations. ${ }^{18}$ Congress intended, by the adoption of generalized language, to provide copyright law with the flexibility to accommodate new media without extensive legislative revision. ${ }^{19}$ It rejected the formalistic approach taken

1717 U.S.C. $\$ 101$ provides:

"Audiovisual works" are works that consist of a series of related images which are intrinsically intended to be shown by the use of machines, or devices such as projectors, viewers, or electronic equipment, together with accompanying sounds, if any, regardless of the nature of the material objects, such as films or tapes, in which the works are embodied ....

"Copies" are material objects, other than phonorecords, in which a work is fixed by any method now known or later developed, and from which the work can be perceived, reproduced, or otherwise communicated, either directly or with the aid of a machine or device. The term "copies" includes the material object, other than a phonorecord, in which the work is first fixed....

A work is "fixed" in a tangible medium of expression when its embodiment in a copy or phonorecord, by or under the authority of the author, is sufficiently permanent or stable to permit it to be perceived, reproduced, or otherwise communicated for a period of more than transitory duration. A work consisting of sounds, images, or both, that are being transmitted, is "fixed" for purposes of this title if a fixation of the work is being made simultaneously with its transmission....

"Literary works" are works, other than audiovisual works, expressed in words, numbers, or other verbal or numerical symbols or indicia, regardless of the nature of the material objects, such as books, periodicals, manuscripts, phonorecords, film, tapes, disks, or cards, in which they are embodied. . . .

"Phonorecords" are material objects in which sounds, other than those accompanying a motion picture or other audiovisual work, are fixed by any method now known or later developed, and from which the sounds can be perceived, reproduced, or otherwise communicated, either directly or with the aid of a machine or device. The term "phonorecords" includes the material object in which the sounds are first fixed....

"Sound recordings" are works that result from the fixation of a series of musical, spoken, or other sounds, but not including the sounds accompanying a motion picture or other audiovisual work, regardless of the nature of the material objects, Id. such as disks, tapes, or other phonorecords, in which they are embodied.

18 See 17 U.S.C. $\$ 101$. The statutory provision establishing compilers' revision rights also lacks media neutrality language. See 17 U.S.C. \$201(c).

19 See Hardy, supra note 1, at 665 . Hardy notes that, prior to the 1976 revisions, the courts and Congress sometimes incorporated new technologies into copyright's subject matter by adding new abstract subject matters (such as dramatic works) and sometimes by adding specific media (such as photographs). Id. at 661-66. 
by the Court in White-Smith in favor of a more pragmatic ${ }^{20}$ approach, granting courts considerable leeway to extend copyright law to cover new technologies.

In establishing fixation as the dividing line between the intangible work and the tangible copy, and declaring fixation to be media neutral, Congress most clearly focused on the possible physical embodiments of the intangible works. The statutory provisions containing media neutrality language specifically refer to material objects such as books, periodicals, disks, and tapes. Copies and phonorecords, the only two recognized categories of embodiments, are defined as material objects, ${ }^{21}$ and the rights of reproduction and distribution are limited to copies and phonorecords. ${ }^{22}$ Certainly, the copyright statute has accommodated new storage media such as audiotapes, videotapes, compact disks (CDs), and digital versatile disks (DVDs). ${ }^{23}$

Broader readings of media neutrality are, however, current and plausible. In general usage, the term "medium" denotes not only physical storage media, but, more generally, systems of communication or entertainment such as the broadcast media. ${ }^{24}$ Media neutrality, in a variety of legal contexts, conveys the meaning that

${ }^{20}$ I employ the common, not the philosophical, usage of the term "pragmatic." Nor have I made a systematic attempt to fashion an approach that is particularly consistent with Richard Posner's principles of pragmatic adjudication. See RICHARD A. POSNER, LAw, PRAGMATISM, AND DEMOCRACY 59-85 (2003). My discussion of the Aimster case illustrates that Posner's pragmatism tracks favorably with the analytical approach advocated herein, though his particular interpretation of the Sony standard for noninfringing uses is more stringent than I would advocate. See infra Part III.C.

${ }^{21}$ H.R. REP. 94-1476, at 5666 states:

'copies' and 'phonorecords' together will comprise all of the material objects in which copyrightable works are capable of being fixed. The definitions of these terms in section 101, together with their usage in section 102 and throughout the bill, reflect a fundamental distinction between the 'original work' which is the product of 'authorship' and the multitude of material objects in which it can be embodied. Thus, in a sense of the bill, a 'book' is not a work of authorship, but is a particular kind of 'copy.' Instead, the author may write a 'literary work,' which in turn can be embodied in a wide range of 'copies' and 'phonorecords,' including books, periodicals, computer punch cards, microfilm, tape recordings, and so forth. It is possible to have an 'original work of authorship' without having a 'copy' or 'phonorecord' embodying it, and it is also possible to have a 'copy' or 'phonorecord' embodying something that does not qualify as an 'original work of authorship.' Two essential elements-original work and tangible object-must merge through fixation in order to produce subject matter copyrightable under the statute.

Id.
22 See 17 U.S.C. $\$ 106$.
23 See Hardy, supra note 1, at 665-66.
24 See MERRIAM WeBSTER's Collegiate Dictionary 771 (11 th ed. 2003). 
law should not favor any particular technology over another. ${ }^{25}$ The language of the House Report suggesting statutory indifference to the "form, manner, or medium" of fixation supports an expansive reading of the term "media neutrality" to mean, in essence, technology neutrality. ${ }^{26}$ I suggest, therefore, that the principle of media neutrality mandates that courts interpreting copyright law, in the absence of explicit congressional guidance regarding particular technologies, ideally should remain neutral with respect to different technologies of reproduction and dissemination, whether those technologies are analog or digital and whether courts face issues of copyrightability or infringement. Transfers of works from one medium to another should not affect copyright protection nor should particular technological configurations be determinative of such protection. This interpretation is consonant with the legislative goal of making copyright law adaptable to new technologies.

Congress retains its prerogative to provide expressly for special treatment of particular technologies by statute, as it has done on occasion in the past. Congress has, for example, elected to treat digital and radio transmissions of sound recordings differentl $y^{27}$ and has adopted special provisions governing cable and satellite television which accord them treatment different from that given to broadcast television. $^{28}$ The history of cable television, in fact, provides another instance of formalist adjudication that forced Congress to take legislative action

${ }^{25}$ The Electronic Signatures in Global and National Commerce Act (E-SIGN), for example, is characterized as media neutral because it does not favor any one electronic signature technology over another. Pub. L. No. 106-229, 114 Stat. 464 (2000) (codified as 15 U.S.C. \ 7003 (2000)); see, e.g., Jane K. Winn, Electronic Commerce Lav: 2001 Developments, 57 Bus. Law. 541, 544 (2001). Provisions of revised Article 9 concerning filing of security interests are similarly characterized. U.C.C. $\$ 9$ (2001); see, e.g., William J. Murphy, Proposal for a Centralized and Integrated Registry for Security Interests in Intellectual Property, 41 IDEA 297, 349 (2002). Even proposals for online gambling regulation have been characterized as media neutral on grounds that on- and off-line gambling should receive similar legal treatment. See Bruce P. Keller, The Game's the Same: Why Gambling in Cyberspace Violates Federal Law, 108 YALE L.J. 1569 (1999).

${ }^{26}$ H.R. REP. 94-1476, at 5665 (1976).

${ }^{27}$ See 17 U.S.C. $\$ 106(6)$ (giving the copyright owner the right to publicly perform sound recordings by means of digital audio transmission). No similar right is accorded for analog broadcast of sound recordings.

${ }^{28}$ See, e.g., 17 U.S.C. $\$ 111(2000)$ (establishing a statutory royalty for secondary transmissions by cable television companies); 17 U.S.C. $\$ 119$ (2000) (codifying special provisions for secondary transmissions by satellite carriers). These provisions deal with centralized transmissions by commercial enterprises, whereas modern digital networks, by their nature, involve decentralized activities by users as well as commercial providers. 
to address a new technology, ${ }^{29}$ which was the scenario that Congress sought to minimize by adopting the principle of media neutrality.

The legislative history of the 1976 Act makes clear that Congress expected copyright law to encompass electronic embodiments of works and that the rule of media neutrality applies to such embodiments. In fact, the foreseeable proliferation of electronic media was a driving force behind adoption of the principle. ${ }^{30}$ It is unlikely that Congress fully understood the consequences of applying its expansive definition of fixation to digitized information. The nature of electronic media and the fluid relationships between intangible works and electronic storage and retrieval systems complicate distinctions between the tangible copy and the intangible work.

\section{B. THE ELECTRONIC CHALLENGE}

Fixation, in digital works, occurs in computer memory as well as on physical media. Computers utilize both permanent read-only memory (ROM), the contents of which cannot be changed, and temporary random access memory (RAM), the contents of which may disappear when the computer is turned off unless captured automatically in the computer's "cache" or "saved" to a physical

${ }^{29}$ Congress enacted 17 U.S.C. $₫ 111$ to resolve an ongoing dispute between the broadcast television industry and cable television industries over the payment of royalties for re-transmission of copyrighted, broadcast works. See Hardy, supra note 1. Prior to adoption of the 1976 revisions, the Supreme Court, taking a formalistic approach, held that such retransmissions were not "performances" within the meaning of the 1909 Act. See Teleprompter Corp. v. Columbia Broad. Sys., Inc., 415 U.S. 394, 181 U.S.P.Q. (BNA) 65 (1974); Fortnightly Corp. v. United Artists Television, Inc., 392 U.S. 390, 158 U.S.P.Q. (BNA) 1 (1968). A strong argument could be made that Congress should adhere more closely to its own prescription for media neutrality. Its periodic interventions on behalf of various powerful industries have produced legislation remarkable both for its complexity (indeed, near-incomprehensibility) and its susceptibility to influence. Technologyspecific fixes to address the copyright crisis du jour do little to improve the law's adaptability to future technological evolution.

${ }^{30}$ During the drafting of the 1976 Act, Congress heard specific testimony concerning the development of electronic storage and retrieval systems. The Register of Copyrights recommended media neutrality as a means of assuring copyright's adaptability to such technologies. Staff of House Comm. on the Judiciary, 89th Cong., Copyright Law Revision Part 6: SUPPLEMENTARY REPORT OF THE REGISTER OF COPYRIGHTS ON THE GENERAL REVISION OF THE U.S. COPYRIGHT LAW; 1965 REvision, BILl 624A (Comm. Print 1965). The 1980 amendments to the Copyright Act brought computer programs within the scope of copyright by adding them to the list of defined works and providing for limitations on the reproduction and adaptation rights in favor of owners of copies of programs. See 17 U.S.C. $\$ \$ 101,117$. These amendments were recommended by the Commission on New Technological Uses of Copyrighted Works (CONTU) which concluded that computer programs were the proper subject matter of copyright. See NAT'L COMM. ON NEW TECHNOLOGICAL USES OF COPYRIGHTED WORKS, FINAL REPORT 1 (1978) [hereinafter CONTU Report]. 
storage medium. Programs and other information that the computer is not currently using are stored. There are many variations on storage architecture. Some computers may cache information on the hard disc and recall it into RAM; others may cache information in a separate memory chip located adjacent to the processing unit. ${ }^{31}$ Often information is stored on magnetic media such as the computer's hard disk, floppy disks, CDs, or DVDs. ${ }^{32}$

Computer programs (software) comprise instructions which cause computers, or other electronic devices, to perform desired functions. ${ }^{33}$ Programs take the form of object code, a binary language of zeros and ones (bits) acting as on-off switches for electrical charges as the programs interact with the machine. ${ }^{34}$ Content such as audiovisual images, musical recordings, or the text of news reports is also captured in this form. ${ }^{35}$ The basic nature of computer programs, particularly when combined with network capabilities, raises several challenges to media-neutral application of copyright law. First, electronic sequences of bits cannot, in all states, readily be characterized as tangible, stable copies or phonorecords for purposes of establishing fixation. Second, electronic media muddy the traditional boundaries between categories of copyrightable works, particularly those separating the original work from later byproducts of the original such as compilations and derivative works. Finally, electronic media permit unprecedented infringement by end users, which enhances tensions among copyright owners, users, and the providers of technologies that enable user infringement.

${ }^{31}$ See I. Trotter Hardy, Computer Ram "Copies": A Hit Or A Myth? Historical Perspectives On Cacbing As A Microcosm Of Current Copyright Concerns, 22 U. DAYTON L. REv. 425, 427 n.5 (1997).

${ }^{32}$ Unlike information in RAM, which consists of electrical pulses, information stored on magnetic media takes the form of magnetic charges. When the information is needed, the computer reads magnetically stored information from permanent storage, translates it into electrical pulses in RAM, and transfers it to the central processing unit which performs the operations called for by a particular program. See Bradley J. Nicholson, The Ghost In The Machine: MAI Sys. Corp. v. Peak Computer, Inc., And The Problem Of Copying In Ram, 10 High TECH. L.J. 147, 148-50 (1995).

${ }^{33}$ See 17 U.S.C. $\$ 101$ ("A 'computer program' is a set of statements or instructions to be used directly or indirectly in a computer in order to bring about a certain result.").

34 See Nicholson, supra note 32, at 149-50.

${ }^{35}$ Unlike traditional media in which music, writings, and images were embodied as physical representations of the recorded work, digital technology reproduces those same sights, sounds, and words as numbers. See Raymond Shih Ray Ku, The Creative Destruction Of Copyright: Napster And The New Economics Of Digital Technology, 69 U. CHI. L. REV. 263, 270 (2002). Music is digitally recorded by measuring the height of the sound wave generated by music at 44,100 times per second and recording those samples instead of physically reproducing the sound wave in the grooves of a vinyl album. Images are reduced to component dots and numbers are assigned to those dots to represent color. Text is the easiest content to digitize. ASCII code, which is almost universally used to digitize text, assigns code numbers to each typewriter character. See NATIONAL RESEARCH COUNCIL, THE Digital Dilemma: INTELIECTUAL PROPERTY IN THE INFORMATION AgE 28-30 (2000). 
1. Tangible Copies. Some commentators view object code not as a true copy but as an intermediate language which translates information into digital form, creating a sort of quasi-copy of the work which enables hardware and software to recreate a copy of the work for display on a computer screen. ${ }^{36}$ Even assuming that object code represents a true copy for copyright purposes, code changes states in a way that prior reproductive technologies did not and its tangibility in some of those states is questionable. ${ }^{37}$ When object code is stored on a physical storage medium, most would probably concede that a tangible fixation of the work represented by the code exists on that medium. ${ }^{38}$ But code also exists in operational states relatively free of permanent storage media. It functions in temporary computer memory and can be transmitted via radio waves, through telephone and cable wires, and across fiber optic networks. ${ }^{39}$ In these situations, object code takes dynamic, evanescent forms.

A particularly thorny question arises with respect to the duration of electronic copies, since copyright requires that the medium of fixation be stable for a period of more than transitory duration. ${ }^{40}$ Significant disputes have arisen over copyright's treatment of temporary RAM copies ${ }^{41}$ and file transmissions. ${ }^{42}$ The

${ }^{36}$ See, e.g., F. Gregory Lastowka, Free Access and the Future of Copyright, 27 RUTGERS COMPUTER \& TECH. L.J. 293, 296, 299 (2001). Lastowka observes that digitization makes all copies less "real" not only in the physical sense, but in terms of declining value. Jane Ginsburg touches on both the materiality and translation problem:

[W] hile digital media in one sense de-materialized copies, by instantly, albeit intangibly, converting any work into a series of $1 \mathrm{~s}$ and 0 s available for receipt in RAM, tecipients not only could perceive the works fleetingly in "real" time, but they also held the power to re-materialize them into retention copies. . . .

Jane C. Ginsburg, From Having Copies to Experiencing Works: the Development of an Access Right in U.S. Copyright Law, COLUM. LAW SCHOOL PUB. LAW \& LEGALTHEORYWORKING PAPER GROUP, Paper Number 8, 2 (2000), available at http://papers.ssrn.com/paper.taf?abstract_id=222493.

37 The tangibility issue is reminiscent of the vanishing common law distinction between trespass and nuisance. Historically, trespass law applied to physical invasions of property, while nuisance law covered "non-physical" invasions such as noxious fumes or loud noise. As modern science teaches, the latter also represent physical, if invisible, phenomena. Similar issues now arise in cases applying the doctrine of trespass to chattels to electronic information gathering. See, e.g., Dan L. Burk, The Trouble with Trespass, 4 J. SMALL \& EMERGING BUS. L. 27 (2000).

${ }^{38}$ See, e.g., Wendy J. Gordon, Fine-Tuning Tasini: Privileges of Electronic Distribution and Reproduction, 66 BROOK. L. REV. 473, 485 n.65 (2000) (observing that fixing a writing on a digital medium such as a $\mathrm{CD}$ or an online database constitutes both fixation and reproduction, but arguing that RAM copies should be considered neither fixed nor reproductions).

${ }^{39}$ Shih Ray Ku, supra note 35, at 271.

40 See 17 U.S.C. $\$ 101$.

${ }^{41}$ See, e.g., Joseph P. Liu, Owning Digital Copies: Copyright Law and the Incidents of Copy Ownership, 42 WM. \& MARY L. REV. 1245, 1249-52, 1252 n.15 (2001) (recognizing that digital copies have a physical existence but categorizing them as "largely intangible" compared to more traditional copies on the basis of their greater manipulability and evanescence). Liu distinguishes between RAM copies 
legislative history of the Copyright Act indicates that temporary instantiations of works in computer memory should not be viewed as fixations. ${ }^{43}$ The Commission on New Technological Uses (CONTU) which recommended copyright law as the primary protective regime for computer programs seemingly advised the opposite. ${ }^{44}$ A number of courts have ruled that RAM copies are fixations, and hence potentially infringing copies. ${ }^{45}$

Notwithstanding substantial scholarly argument to the contrary, ${ }^{46}$ the pronounced tendency in the courts is to treat even evanescent digital code as sufficiently material and stable to constitute fixation. Indeed, the courts have generally dealt with digital code as a rough functional equivalent of a traditional analog copy or phonorecord. ${ }^{47}$ This result is consistent with media neutrality.

and copies stored on magnetic storage media which are more clearly fixed. He speculates on whether the stored digital copy of magnetic zeros and ones could be distinguished entirely from its storage medium, but notes that prior media like audio and video tapes also captured magnetic patterns (analog rather than digital) on physical substrates. Id. at $1304 \mathrm{n} .203,1308$ n.217.

${ }^{42}$ See, e.g., R. Anthony Reese, The Public Display Right: The Copyright Act's Neglected Solution To The Controversy Over Ram "Copies", 2001 U. ILL. L. REV. 83, 128 (2001) (arguing that the transmission of encoded data over the Internet no more makes a copy of the work than does a television broadcast of the work).

${ }^{43}$ The House Report provides: "[T] he definition of 'fixation' would exclude from the concept purely evanescent or transient reproductions such as those projected briefly on a screen, shown electronically on a television or other cathode ray tube, or captured momentarily in the 'memory' of a computer." H.R. REP. NO. 94-1476, at 5666. The reference to computer memory, while not specific, appears to exclude volatile RAM memory and, by analogy to television broadcasts, the reference to transient reproductions would appear to exclude electronic transmissions.

${ }^{44}$ In somewhat ambiguous language, CONTU's report observed that "the placement of a copyrighted work into a computer ... is the preparation of a copy .... Because works in computer storage may be repeatedly reproduced, they are fixed and, therefore, are copies ...." CONTU Report, supra note 30 , at 22 . Niels Schaumann observes that, at the time the CONTU report was written, the term "memory" was frequently used to mean any form of computer storage, whether volatile or permanent. Niels Schaumann, Copyright Infringement and Peer-To-Peer Tecbnology, 28 WM. MITCHELL L. REV. 1001, 1026 n.100 (2002). He suggests that CONTU may have been referring to disk storage rather than to RAM storage. Id.

${ }^{45}$ See, e.g., MAI Sys. Corp. v. Peak Computer, Inc., 991 F.2d 511, 518, 26 U.S.P.Q.2d (BNA) 1458, 1463-64 (9th Cir. 1993); Intellectual Reserve, Inc. v. Utah Lighthouse Ministry, Inc., 75 F. Supp. 2d 1290, 1294, 53 U.S.P.Q.2d (BNA) 1425, 1428 (D. Utah 1999); Stenograph L.L.C. v. Bossard Assocs., 144 F.3d 96, 101-02, 46 U.S.P.Q.2d (BNA) 1936, 1940-41 (D.C. Cir. 1998); Advanced Computer Servs. of Mich. v. MAI Sys. Corp., 845 F. Supp. 356, 363, 30 U.S.P.Q.2d (BNA) 1443, 1448-49 (E.D. Va. 1994).

46 See, e.g., Gordon, supra note 38 , at 475 ; Liu, supra note 41 , at 1252 ; Reese, supra note 42 , at 84 .

47 See, e.g., UMG Recordings, Inc. v. MP3.com, Inc., 92 F. Supp. 2d 349, 350, 54 U.S.P.Q.2d (BNA) 1668, 1670 (S.D.N.Y. 2000) (rejecting the argument that MP3 files were not reproductions because the sounds they captured were not physically identical to the sounds on the originals, and noting that the difference was not detectible by the human ear). Id. n.1. The opinion is somewhat vague as to whether MP3 files are reproductions or derivative works, referring to the copyright 
Electronic impulses are, after all, physical phenomena and their effects, while not directly perceptible, are certainly so with the aid of a machine or device. The evanescence of code is, however, decidedly a factor in the videogame cases discussed infra. ${ }^{48}$

2. Original Works and Their Byproducts. Electronic media inherently pose problems in defining the byproducts of original works, such as derivative works, collective works, and revisions. Bits may represent content (text, graphic images, and the like) or encode functional computer programs-thereby intertwining content and method of delivery. ${ }^{49}$ Congress was untroubled by the fact that an embodiment in a particular medium might recreate the work indirectly by operating a machine. Works captured in electronic media, however, are usually perceivable only through a machine or device enabled by software, which is a separately copyrightable artifact. ${ }^{50}$ The addition of software to content may trigger re-categorization of the resulting work, for copyright purposes, as a derivative or collective work.

Traditional copyright assumes the existence of an original work, captured in a particular medium, which may later undergo simple transfer into new media, but may also be adapted into new derivative works or incorporated into compilations. Under existing case law, change of medium alone is insufficient to create a derivative work, but addition of new, copyrightable material may create a potentially infringing derivative..$^{51}$ Mere translation of a work from analog to electronic media, or from one electronic format to another, may require the addition of independently copyrightable software even though no changes are

owners' right to license reproductions for derivative markets. See id.

${ }^{48}$ See infra Part III.A.

${ }^{49}$ Micro Star v. Formgen, Inc., 154 F.3d 1107, 98 U.S.P.Q.2d (BNA) 1026 (9th Cir. 1998) illustrates the dual function of bits as representations of content and operational elements of software programs. The MAP files at issue did not encode actual screen displays, but rather instructed the game engine and art files to create the displays. See infra Part III.A.4. In theory, current copyright law treats digitized content and software in the same way, norwithstanding their functional differences.

${ }^{50}$ This is true of all products designed for use on computers, which require software to enable the use of content (or indeed to instruct the machine to do anything at all). Special-purpose digital devices may have such capabilities built into hardware though, increasingly, even special-purpose devices such as VCRs incorporate some computer-like capabilities for storage and computation. The line between software and hardware is often indistinct. See NAT'L RESEARCH COUNCIL, supra note 35 , at 44 .

51 See, e.g., L. Batlin \& Son, Inc. v. Snyder, 536 F.2d 486, 491, 189 U.S.P.Q. (BNA) 753, 756-57 (2d Cir. 1976). Similarly, mere change of medium has been held not to be transformational for purposes of fair use analysis. See, e.g., Infinity Broadcast Corp. v. Kirkwood, 150 F.3d 104, 108, 47 U.S.P.Q.2d (BNA) 1295, 1297-98 (2d Cir. 1998) (retransmission of radio broadcast over telephone lines is not transformative); UMG Recordings, 92 F. Supp. 2d at 351 (S.D.N.Y. 2000) (reproduction of audio CD into MP3 format is not transformative). 
made in content, arguably requiring classification of the work as a derivative or collective work rather than a mere copy. One court has suggested in dictum that the addition of software in transformation of a work from an analog to a digital medium may be a sufficient variation to create a new, potentially infringing collective work. $^{52}$

The fluidity of content captured in electronic media further complicates the traditional distinction between original works and their byproducts since the same data may be reorganized to produce any number of products, such as printed newspapers, $\mathrm{CDs}$, or individual articles displayed online. The data may undergo multiple conversions not only from analog to digital media, or vice versa, but also into different electronic formats. ${ }^{53}$ Identification of a particular manifestation of the work as original, derivative, or a revision becomes problematic. The difficulty of adhering to traditional distinctions between original works and their byproducts plays a role in the videogame and database cases. ${ }^{54}$

3. The User-Centric Universe. Finally, electronic media give users, as well as publishers, opportunities both to produce perfect copies and to modify works in ways not possible in prior media. When Internet access is added to electronic capabilities, users also become mass distributors of works. Traditional copyright law primarily targeted enforcement against institutional copiers and distributors of works, not end users. While analog copying technologies such as the photocopier and home taping presented serious challenges to the gatekeeper model of enforcement, digital technologies raised the stakes immeasurably. Reluctant to sue their own customers, copyright owners have often chosen to litigate against the providers of new technologies of reproduction and dissemination, attempting to curtail the use of such technologies. ${ }^{55}$ Such suits bring into play a set of competing policy concerns, forcing judicial consideration not only of traditional copyright policies balancing incentives against access, but also of policies favoring technological innovation.

The courts in many of the cases discussed herein struggle with the allocation of liability between potentially infringing users and the technology providers who enable their activities. The most certifiable embodiments of the works in question appear, at users' command, on their screens or hard drives, placing users at the

52 See Greenberg v. Nat'l Geographic Soc'y, 244 F.3d 1267, 1273 n.12, 58 U.S.P.Q.2d (BNA) 1267,1272 n.12 (11th Cir. 2001).

${ }_{53}$ For example, music stored on digital CDs can be converted into MP3 files. The district court in UMG Recordings referred to such electronic reformating as a medium change notwithstanding that both formats were electronic in nature.

${ }^{54}$ See infra Parts III.A and B.

${ }^{55}$ See Mark A. Lemley \& Anthony R. Reese, Reducing Digital Copyright Infringement Without Restricting Innovation, 56 STAN. L. REV. 1346, 1373-78 (2004); Tim Wu, When Code Isn't Law, 89 VA. L. REV. 679, 712-14 (2003). 
center of infringement actions in ways not anticipated by traditional copyright law. The Supreme Court first faced the issue of technology-enabled consumer infringements in Sony Corp. of America v. Universal City Studios. ${ }^{56}$ In that case, the Court created an analytical framework which imposes some limitations on the courts' authority, granted under the principle of media neutrality, to extend copyright protection to new technologies.

\section{SONY AND SECONDARY LIABILITY}

In all of the cases discussed herein, the defendants are providers of devices or software that enable consumer activities which may infringe one or more of the copyright owner's rights. Consequently, contributory and vicarious infringement claims are common. The Copyright Act contains no express statutory language establishing requirements for contributory or vicarious liability for infringement, but courts have established such requirements under general rules for secondary liability. ${ }^{57}$ The Supreme Court's decision in Sony remains the most influential case on secondary liability both for its adoption of the staple article of commerce doctrine and for its interpretation of fair use in the context of third party products or services which enable user infringements. The Sony Court refers interchangeably to both contributory and vicarious infringement, though, on its facts, the case applies only to contributory infringement. ${ }^{58}$

In Sony, movie studios sought to enjoin the sale of videotape recorders on the grounds that they contributed to infringement by home users who taped copyrighted material from broadcast television. ${ }^{59}$ The Court adapted the staple article of commerce doctrine from patent law, holding that copyright owners may not preclude distribution of technologies which might be used to infringe copyrights but which also have substantial noninfringing uses. ${ }^{60}$ In such cases, courts should await legislative guidance. Justice Stevens observed:

The judiciary's reluctance to expand the protections afforded by the copyright without explicit legislative guidance is a recurring

56464 U.S. 417, 220 U.S.P.Q. (BNA) 665 (1984).

57 See id. at 435. A contributory infringer is one who, with knowledge or reason to know of likely infringement by others, materially contributes to, causes, or induces the direct infringement. Id. A vicarious infringer is one with the right and ability to control the infringers who benefits financially from the infringement. Id.

${ }_{58}^{58}$ See Stacy L. Dogan, Is Napster a VCR? The Implications of Sony for Napster and Other Intermet Technologies, 52 HASTINGS L.J. 939, 940 (2001). The Ninth Circuit limits Sony to its facts in $A \dot{\sigma} M$ Records, Inc. v. Napster, 239 F.3d 1004, 57 U.S.P.Q.2d (BNA) 1729 (9th Cir. 2001).

59 Sony, 464 U.S. at 419.

${ }^{60}$ Id. at 442. 
theme.... Sound policy, as well as history, supports our consistent deference to Congress when major technological innovations alter the market for copyrighted materials. Congress has the constitutional authority and the institutional ability to accommodate fully the varied permutations of competing interests that are inevitably implicated by such new technology. ${ }^{61}$

Applying the standard four-factor test for fair use, ${ }^{62}$ the Court read the doctrine to presumptively favor noncommercial uses such as home taping. In the context of the case, the Court found that time-shifting ${ }^{63}$ by users was a fair use and, therefore, a substantial noninfringing use. ${ }^{64}$ While Sony announced a broad policy protective of technological innovation, the court crafted its actual holding narrowly, focusing only on time-shifting and emphasizing the fact that broadcasts were already made available free to the public. ${ }^{65}$ The scope and applicability of Sony has bedeviled lower courts ever since ${ }^{66}$ and recurs as a constant refrain in the storage-and-retrieval cases.

Sony balanced the necessity of copyright incentives for content creators against policies favoring non-interference with technological innovation in unrelated fields which might benefit society as a whole. This balancing of interests echoes the utilitarian approach to copyright, constitutionally based in the Copyright Clause, which mandates that the creation of incentives for creators, through limited monopolies, must be offset against the public interest in broad dissemination of works. ${ }^{67}$ The development of digital media of reproduction and dissemination may threaten the balance of copyright incentives and access, but Sony warns that innovation policy must also be weighed by courts.

The Sony Court's refusal to read copyright too expansively to encompass new technologies absent specific legislative guidance creates a useful tension with the media neutrality principle. On the one hand, the congressional exhortation to media neutrality encourages courts to interpret copyright law flexibly to

${ }^{61}$ Id. at 431.

62 See 17 U.S.C. $\$ 107$ (2000). The four factors are: "the purpose and character of the use ... the nature of the copyrighted work ... the amount and substantiality [of the copyrighted work used by the defendant] ... [and] the effect of the use upon the market for or value of the copyrighted work." Id.

${ }^{63}$ Time-shifting means taping a program in order to watch it at a later time.

${ }^{64}$ Sony, 464 U.S. at $442-43$.

${ }^{65}$ Id. at $448-50$.

${ }_{66}$ See Dogan, supra note 58, at 940,942-43 ("Neither the Supreme Court nor subsequent lower court decisions have elucidated what kinds of products or services can qualify as staple articles of commerce, nor have they provided a framework for deciding whether such an article has a 'substantial non- infringing use.' ").

${ }^{67}$ See U.S. CONST. art. I, $₫ 8 \mathrm{cl}$. 8. 
Tussey: Technology Matters: The Courts, Media Neutrality, and New Technol

encompass new technologies. Sony does not necessarily conflict with this principle. It simply forces courts to consider the countervailing interest in innovation policy, establishing a sort of border, the substantial noninfringing use, beyond which courts should not venture without legislative guidance. Both the media neutrality principle and the Sony framework represent steps away from formalistic interpretation of black letter law toward a more empirical, pragmatic approach to judicial decisionmaking in new technology cases. The cases that follow, however, illustrate difficulties later courts have faced in applying Sony while maintaining media neutrality, when faced with new electronic storage and retrieval systems.

\section{THE CASES}

In this part, three sets of cases illustrate varying judicial approaches to electronic storage and retrieval systems. The cases involve video game enhancements, database compilations, and internet file sharing applications and raise similar questions regarding the impact of system architecture on copyright infringement claims. In each set of cases, at least one court, in a well-known and important decision, relies heavily on system characteristics in seeming contravention of the principle of media neutrality. The courts in Micro Star v. Formgen, Inc., ${ }^{68}$ New York Times Co. v. Tasini, ${ }^{69}$ and $A \mathscr{\sigma} M$ Records, Inc. v. Napster, Inc., ${ }^{70}$ are the chief offenders in this regard.

\section{A. VIDEOGAME ENHANCEMENTS-DIFFERENT TREATMENT FOR SIMILAR} TECHNOLOGIES

The central cases in this segment, Lewis Galoob Toys, Inc. v. Nintendo of America, Inc., ${ }^{71}$ and Micro Star v. Formgen, Inc., ${ }^{72}$ were decided six years apart by the Ninth Circuit. Mention must also be made of an older case, Midway Mfg. Co. v. Artic International, Inc. ${ }^{73}$ decided by the Seventh Circuit when both the current Copyright Act and the videogame industry were in their infancies. The Midway and Galoob courts employ balanced analyses, while Micro Star illustrates a technology-centered analysis.

${ }_{68}^{6} 154$ F.3d 1107, 48 U.S.P.Q.2d (BNA) 1026 (9th Cir. 1998).

69533 U.S. 483, 59 U.S.P.Q.2d (BNA) 1801 (2003).

${ }^{70} 239$ F.3d 1004, 57 U.S.P.Q.2d (BNA) 1729 (9th Cir. 2001).

${ }^{71} 964$ F.2d 965, 22 U.S.P.Q.2d (BNA) 1857 (9th Cir. 1992).

${ }^{72} 154$ F.3d 1107, 48 U.S.P.Q.2d (BNA) 1026 (9th Cir. 1998).

73704 F.2d 1009, 218 U.S.P.Q. (BNA) 791 (7th Cir. 1983). 
All three cases involve unauthorized enhancements to copyrighted videogames and raise issues concerning the scope of the derivative works right. A derivative work is "a work based upon one or more preexisting works, such as a translation, musical arrangement, dramatization, fictionalization, motion picture version, sound recording, art reproduction, abridgment, condensation, or any other form in which a work may be recast, transformed, or adapted." ${ }^{\text {. }}$ The statutory definition is generally conceded to be hopelessly overbroad, and courts have struggled to impose limits on it. $^{75}$ In general, a mere change of medium is not sufficient to create a derivative work, but a medium change accompanied by a nontrivial variation from the original may do so. ${ }^{76}$ The derivative work, then, must be substantially similar to the original, but add something new. In the games cases, plaintiffs rely on arguments that enhanced game displays constitute unauthorized derivative works. Particularly in the two earliest opinions, the courts were faced with scenarios in which uncertain legal doctrine must be applied to new, and little understood, technologies. Read sequentially, the cases offer a window into the rapid pace of technological change in the videogame industry.

Midway predates the popularization of videogame consoles and cartridges for home use- the arcade game technology described by this court now seems almost as antique as the piano roll. ${ }^{77}$ The defendant, Artic, manufactured printed circuit boards which, when substituted for the original circuit board, speeded up the rate

${ }^{74} 17$ U.S.C. $\$ 101$ (2002).

75 See Melville B. Nimmer \& David Nimmer, I Nimmer ON COPYRIGHT $\$ 3.01$ (2002).

${ }^{76}$ See, e.g., L. Batlin \& Son, Inc. v. Snyder, 536 F.2d 486, 491, 189 U.S.P.Q. (BNA) 753, 756-57 (2d Cir. 1976).

77 The court describes what was, at the time, state-of-the-art technology as follows:

Plaintiff manufactures video game machines. Inside these machines are printed circuit boards capable of causing images to appear on a television picture screen and sounds to emanate from a speaker when an electric current is passed through them. On the outside of each machine are a picture screen, sound speaker, and a lever or button that allows a person using the machine to alter the images appearing on the machine's picture screen and the sounds emanating from its speaker. Each machine can produce a large number of related images and sounds. These sounds and images are stored on the machine's circuit boards-how the circuits are arranged and connected determines the set of sounds and images the machine is capable of making. When a person touches the control lever or button on the outside of the machine he sends a signal to the circuit boards inside the machine which causes them to retrieve and display one of the sounds and images stored in them. Playing a video game involves manipulating the controls on the machine so that some of the images stored in the machine's circuitry appear on its picture screen and some of its sounds emanate from its speaker.

Midway, 704 F.2d at 1010. 
of play of one of Midway's games. ${ }^{78}$ Midway arose before the copyrightability of programs embodied in physical circuits was well-established. Arctic's circuit boards literally copied Midway's program code, but Midway had registered only its audiovisual displays, ${ }^{79}$ forcing the court to address the case from the derivative works standpoint despite the literal copying of Midway's code.

The derivative works question was one of first impression. Artic argued that merely speeding up the rate of play of a game could not create a derivative work. Analogizing the speeded-up video game to speeded-up play of a phonograph record, the court admitted that merely speeding up a recording would not likely create an unauthorized derivative work. The court, however, found a critical distinction between recordings and videogames in that there was a lucrative market for speeded-up videogames, but none for speeded-up sound recordings. ${ }^{80}$ Consequently, Artic's "fast" game was a substantially different product from the original work and must be considered an unauthorized derivative work of Midway's game. Midway's licensees, the arcade owners, lacked authorization to create derivative works and were direct infringers; Artic committed contributory infringement by selling the circuit boards. ${ }^{81}$

Acknowledging that videogames did not fit readily within the statutory definition of derivative works, the court found that the definition could appropriately be stretched to incorporate them, reciting the congressional intent that the new Copyright Act be construed flexibly to cover new technologies. ${ }^{82}$

${ }^{78}$ Artic produced a circuit board which produced sounds and images nearly identical to plaintiffs Pac-Man game. The court's discussion centers, however, on the speeded-up version of Galaxian, with little specific discussion of the Pac-Man simulation. Id. at 1011.

${ }^{79}$ It is clear from the district court opinion that Artic's circuit boards copied much of the code on Midway's ROM chips. See Midway Mfg. Co. v. Artic Int'l, Inc., 547 F. Supp. 999, 1004, 216 U.S.P.Q. (BNA) 413, 417 (D.C. Ill. 1982). In this case and a subsequent case involving a substitute circuit board for Pac-Man games, the district court provided a much more detailed analysis of the technology involved in Midway's arcade games. See Midway Mfg. Co. v. Strohon, 564 F. Supp. 741, 219 U.S.P.Q. (BNA) 42 (N.D. Ill. 1983). The circuit boards were composed of a number of ROM chips containing different sets of instructions directing sequence of play and creation of displays. Computer programs are protected by copyright as literary works. See 17 U.S.C. $\$ 101$. Courts have recognized the audiovisual display produced by the program as a separate copyrightable work. See, e.g., Stern Elecs., Inc. v. Kaufman, 669 F.2d 852, 213 U.S.P.Q. (BNA) 443 (2d Cir. 1982).

${ }^{80}$ Midway, 704 F.2d at 1013-14. The court obviously did not anticipate the phenomenon of music sampling.

${ }^{81}$ Id. at 1013. Here the court seems to have confused the arcade owners (the licensees) with the actual players. Direct infringement would presumably occur when players activated and interacted with the game circuit board, producing derivative audiovisual works on screen. The arcade owner, like the manufacturer, would probably be considered a contributory infringer, i.e., one who with actual knowledge of likely infringement materially contributed to the direct infringement, or a vicarious infringer, i.e., one who could control the infringements and profited from them.

${ }^{82}$ Id. at 1011. 
The court referenced earlier cases involving the copyrightability of screen displays which relied on the media neutrality language incorporated in the definition of audiovisual works. ${ }^{83}$

The Midway court devotes little ink to in-depth discussion of technological details. Rather, it engages in fairly straightforward application of derivative works principles as informed by a policy favoring flexible, media-neutral construction designed to bring new technologies within the scope of copyright law. Notably, the court does not discuss the need for a physical embodiment of a derivative work, an issue which becomes critical in the Ninth Circuit cases. It does provide an early airing of some recurring themes in the storage and retrieval cases: the use of analogies to prior, non-digital technologies ${ }^{84}$ and the importance of market impact. Midway predates the Sony decision and the concerns with balancing copyright incentives against technological innovation which come to the fore in the Ninth Circuit cases.

By the time the Ninth Circuit faced the game enhancement question in Galoob, ${ }^{85}$ the videogame industry had developed the familiar format in which players interact with copyrighted games through a console and game cartridge, viewing the game displays on home television screens. Galoob marketed a popular add-on device, the Game Genie, which, like the circuit board in Midway, enhanced the level of play of the plaintiff s copyrighted videogames. The Game Genie, however, was a plug-in device inserted between the console and the game cartridge and neither copied Nintendo's code nor replaced its existing products. ${ }^{86}$

83 See, e.g., Williams Elecs., Inc. v. Artic Int'l, Inc., 685 F.2d 870, 215 U.S.P.Q. (BNA) 405 (3d Cir. 1982) (holding audiovisual display to be fixed for purposes of copyright protection); of. WGN Cont'l Broad. Co. v. United Video, Inc., 693 F.2d 622, 216 U.S.P.Q. (BNA) 97 (7th Cir. 1982) (holding that television station owned copyright in the content of its broadcast but not the vertical blanking interval which was part of the method of transmission).

${ }^{84}$ With regard to fixation and its phonograph analogy, the court pays no heed to the fact that playing a phonograph at faster than normal speed produces no fixed embodiment of the speeded-up version, whereas fast Galaxian was embodied in a printed circuit.

${ }_{85}$ Galoob, 964 F.2d 965.

${ }^{86}$ Players using the Genie could augment the powers of their characters by, for example, increasing speed of movement, adding lives, and allowing the character to float above obstacles. As the court describes the Genie's functionality:

The player controls the changes made by the Game Genie by entering codes provided by the Game Genie Programming Manual and Code Book. The player also can experiment with variations of these codes. The Game Genie functions by blocking the value for a single data-byte sent by the game cartridge to the central processing unit in the Nintendo Entertainment System and replacing it with a new value. If that value controls the character's strength, for example, then the character can be made invincible by increasing the value sufficiently.... The Game Genie does not alter the data that is stored in the game cartridge. Its effects are temporary. 
Nintendo argued that Midway resolved the infringement issue; the Genie produced an unauthorized derivative work and Galoob was a contributory infringer. The Ninth Circuit, however, deployed a more complex analysis of the statutory provisions, the challenged technology, and, post-Sony, issues of innovation policy and fair use.

The definition of a derivative work, the court held, required not only that the derivative work be substantially similar to the underlying work but also that it must incorporate the protected work in some concrete or permanent form. ${ }^{87}$ To confuse matters, the court added that incorporation in a concrete or permanent form need not necessarily rise to the level of a fixation under the act, noting that, unlike the definition of copies, the definition of derivative works contained no reference to a fixation requirement. ${ }^{88}$

The Game Genie enhanced the displays originating in Nintendo's game cartridges, but the modified displays were not captured by the Genie in any concrete or permanent form. Consequently, the displays could not be derivative works. The court rejected Nintendo's argument that the Game Genie's displays were fixed in the device's hardware and software, noting that the Game Genie alone could not produce a display at all, but must be used in conjunction with Nintendo's console and cartridge. ${ }^{89}$ The court distinguished Midway noting that

Id. at 967 . The district court opinion contains a more complete description of the device and its various programming modes. See Lewis Galoob Toys, Inc. v. Nintendo of Am., Inc., 780 F. Supp. 1283, 20 U.S.P.Q.2d (BNA) 1662 (N.D. Cal. 1991).

${ }^{87}$ The court observed that the examples of derivative works listed in the definition all physically incorporate the underlying work and that the Act's legislative history similarly indicated that the infringing work must incorporate a portion of the copyrighted work in some form. Galoob, 964 F.2d at 967 .

${ }^{88}$ Id. at 967-68. Nimmer observes that this pronouncement is dictum, given that the court found that the Game Genie created no derivative work, and that the Galoob court itself tended to backslide towards a fixation standard throughout its opinion. See II Nimmer \& Nimmer, supra note $75, \$$ 8.09[A. As written, however, the opinion sets different standards for protectability and infringement of derivative works, requiring fixation for the former but something less for the latter. The court left unanswered the puzzling question how a concrete, permanent incorporation of the underlying work might fail to meet the broad statutory definition of fixation. Despite some legislative history hinting to the contrary, Nimmer would require fixation for infringement of the derivative works right as well as for protection of authorized derivative works. Id. The Register of Copyrights recently adopted a similar view, noting that, legislative history to the contrary, the language of the statute requires that infringing derivative works be fixed because derivative works are works and the statute says that works are created upon fixation. See The Family Morie Act of 2004: Hearing on H.R 4586 Before the House Subcomm. on Courts, the Intemet, and Intellectual Prop., House Comm. on the Judiciary, 108th Cong. (2d Sess. 2004) (statement of MaryBeth Peters, Register of Copyrights).

${ }^{89}$ Galoob, 964 F.2d at 968 . Nintendo made an argument loosely based on media neutrality language in the definition of audiovisual works, urging the court to compare the original displays with the altered displays. See id. The court noted, however, that the only relevant issue was whether the Genie was a derivative work, not whether it was an audiovisual work, since both the original and 
Artic's circuit board both copied and replaced Midway's original board. The Game Genie, in the court's view, did neither. ${ }^{90}$

Citing Sony, the Galoob court found that stretching the definition of derivative works to include the displays triggered by the Genie might chill innovation, preventing the development of useful add-on programs by categorizing them as derivatives of basic applications. ${ }^{91}$ Having disposed of any infringement claim, the court nonetheless went on, in dicta, to do a full Sony-based fair use analysis, applying the statutory factors with a focus on the potential direct infringers, who were home gamers. ${ }^{92}$ The court refused to read Sony narrowly, construing it to stand for the proposition that a party who distributes a work may not thereafter dictate how it is enjoyed. The court found home users' activities to be fair use and, by extension, Galoob could not be guilty of contributory infringement. ${ }^{93}$

Despite the differences in implementing technologies, the devices in Midway and Galoob are close functional equivalents which one might expect to receive similar treatment in infringement actions. The Galoob court's policy favoring technological innovation in other markets, however, stands in marked contrast to Midway's policy favoring extension of copyright protection to new technologies. While system architecture is more important in Galoob's analysis than in Midway's, the court does not rely entirely on it. By defining the standard for derivative works infringement to require something akin to a fixation, and emphasizing the evanescent quality of the Genie's code, Galoob achieves its policy goal.

Add-on manufacturers, at least in the Ninth Circuit, must have been reassured that the development of game enhancements that did not physically incorporate any protected material would not present infringement difficulties. However, six years later, the Ninth Circuit addressed a different technology of game enhancement and refined, or revised, the rules.

By the time Micro Star ${ }^{94}$ reached the Ninth Circuit, yet another variant of videogame technology had become popular: the computer-based game distributed in physical copies or over the Internet. Formgen owned the copyright

altered displays were produced by Nintendo's game cartridge. Id. at 969 .

${ }^{90}$ Id. at 968-69. The latter distinction is not entirely convincing-Midway had, after all, already been paid for its machine, including circuit board, just as Nintendo had already been paid for its console and game cartridge. And while the codes triggering the enhanced displays did not reside permanently in the Genie itself, they were certainly fixed in the Genie's manual.

${ }^{91}$ Id. at 969.

${ }_{92}$ Id. at $969-72$. Finding family use of the Game Genie to be noncommercial, the court applied Sony's presumption in favor of fair use in weighing the purpose-of-use factor. Id. On the critical market impact factor, the court approved the district court's findings that Nintendo had not issued or considered issuing altered games and had failed to establish the likelihood of such markets, a finding which appears rather counterfactual given the popularity of the Game Genie itself. Id.

93 Id. at $970-72$.

${ }^{94}$ Micro Star v. Formgen, Inc., 154 F.3d 1107, 98 U.S.P.Q.2d (BNA) 1026 (9th Cir. 1998). 
in the popular first-person game Duke Nukem. Formgen invited users to create new levels and post them on the Internet, subject to a license term that such new levels should not be distributed commercially. ${ }^{95}$ Micro Star downloaded 300 of these user-created levels, which were embodied in MAP files, fixed them on CDs, and sold them under the name Nuke It. Micro Star, doubtless confident that it would be protected under Galoob, sought a declaratory judgment that Nuke It did not infringe Formgen's copyrights in Duke Nukem. ${ }^{96}$

The critical question on appeal, as in Galoob, was whether the enhancement was an infringing derivative work. The answer, the court noted (undoubtedly to Micro Star's surprise) was "not obvious." ity of the MAP files which instructed Formgen's game engine to go to its art library and create the visual displays for each new level. ${ }^{98}$ Micro Star argued that since the MAP files did not incorporate any protected material belonging to Formgen and the enhanced displays were nowhere captured in concrete form, the

${ }^{95}$ Though the fact is not mentioned by the court of appeals, Formgen included a build editor in its software and provided instructions on how to create new levels and save them as MAP files. A user must have a registered version of Duke Nukem to use files created with the build editor. Screen messages frequently reminded users about the editor and encouraged them to share new levels with friends or upload them to the Internet. See Micro Star v. Formgen, Inc., 942 F. Supp. 1312-15 (S.D. Cal. 1996).

${ }^{96}$ Following what seemed to be the Ninth Circuit's teaching in Galoob, the district court found that Nuke It was not a derivative work and therefore did not infringe, though the court did find infringement in Micro Star's use on its packaging of screen shots of the new levels, which displayed Duke Nukem characters. Micro Star, 154 F.3d at 1109.

${ }^{97}$ Id. at 1110.

${ }^{98}$ The Ninth Circuit's description of the technology:

The game consists of three separate components: the game engine, the source art library and the MAP files. The game engine ... tells the computer when to read data, save and load games, play sounds and project images onto the screen. In order to create the audiovisual display for a particular level, the game engine invokes the MAP file that corresponds to that level. Each MAP file contains a series of instructions that tell the game engine (and, through it, the computer) what to put where. For instance, the MAP file might say scuba gear goes at the bottom of the screen. The game engine then goes to the source art library, finds the image of the scuba gear, and puts it in just the right place on the screen. The MAP file describes the level in painstaking detail, but it does not actually contain any of the copyrighted art itself; everything that appears on the screen actually comes from the art library .... When the player selects one of the N/I levels, the game engine references the N/I MAP files, but still uses the $D / N-3 D$ art library to generate the images that make up that level.

Id. The court did note that, in actuality, the interaction between the three components involves communication of instructions, not physical movement of images. Id. at n.3. 
protection extended to the Game Genie should likewise shelter Nuke It. ${ }^{99}$ The court disagreed.

Rejecting Micro Star's argument that, like the Game Genie, Nuke It merely replaced old values (the original MAP files) with new values (Nuke It s MAP files), ${ }^{100}$ the court observed that the MAP files described each new level in great detail and found such description sufficient to embody the audiovisual displays in a concrete form. ${ }^{101}$ The court gives us little insight here as to the functional difference between re-creatable numerical codes stored in print and entered into the Game Genie to trigger certain displays, and electronic code stored in MAP files to do precisely the same thing. If the Genie's codes (and combinations thereof) can be reentered, one could certainly argue that they describe audiovisual displays quite as completely, though not as efficiently, as Nuke It's MAP files.

Having found a concrete embodiment, the court applied the standard infringement test. Since the displays triggered by the MAP files were substantially similar to Formgen's, Nuke It created an infringing derivative work and Micro Star was a direct, not a contributory, infringer. ${ }^{102}$ The court specifically rejected Micro Star's argument that the MAP files contained no protected expression since they did not contain the actual art files. ${ }^{103}$ Having indulged in micro-analysis of the technology, the court leapt to macro-analysis of content noting that the new story lines adapted the original story and characters, thereby infringing on Formgen's rights to control sequels. ${ }^{104}$ In a truncated analysis, the court turned down Micro

${ }^{99}$ Id. at $1110-11$.

${ }^{100} \mathrm{Id}$.

101 The court explained,

whereas the audiovisual displays created by Game Genie were never recorded in any permanent form, the audiovisual displays generated by $\mathrm{D} / \mathrm{N}-3 \mathrm{D}$ from the N/I MAP files are in the MAP files themselves. In Galoob, the audiovisual display was defined by the original game cartridge, not by the Game Genie; no one could possibly say that the data values inserted by the Game Genie described the audiovisual display. In the present case the audiovisual display that appears on the computer monitor when a N/I level is played is described-in exact detail-by a N/I MAP file ... an exact, down to the last detail, description of an audiovisual display ... counts as a permanent or concrete form for purposes of Galoob.

Id. at 1111-12.

${ }^{102}$ Id. Since the displays came from Formgen's art files, they could hardly fail to be substantially similar. Lydia Loren notes that the court's interpretation basically dispenses with the substantial similarity test in cases involving add-on enhancements. See Lydia Pallas Loren, The Changing Nature of Derivative Works in the Face of New Tecbnologies, 4 J. SMALL \& EMERGING BUS. L. 57, 73-74 (2000).

${ }^{103}$ Micro Star, 154 F.3d at 1112.

${ }^{104}$ Id. On its face, this argument appears to be worthier than the technology-based argument the court primarily relies on, but it creates difficulties of its own because of Formgen's license. Under current law, the new levels constitute derivative works based on the original game; reproduction or 
Star's fair use defense, weighing all four factors against Micro Star, with little discussion of policies favoring innovation or incentives. ${ }^{105}$

The court's analysis glosses over the similarities between the Game Genie and Nuke It. Like the Game Genie, Micro Star's MAP files constituted programmatic instructions, not content, and were useless without the plaintiffs original software. Functionally, they were equivalents in the sense that both products prompted the original software to produce game enhancements. Moreover, the code copied by Micro Star, as well as the new story lines it triggered, were created by users with Formgen's express approval and appear to be authorized derivative works which Micro Star appropriated from the users. Under the Circuit's test for derivative works infringement, it is difficult to see how Micro Star could have been guilty of direct infringement against Formgen.

While Midway can be readily distinguished on the basis of literal copying, the Ninth Circuit cases are not easily reconciled. Both the Game Genie and the MAP files are integrated works which interact with original works to change the user's experience of the original. ${ }^{106}$ The divergent results in the cases seem to indicate that an add-on manufacturer's potential liability for infringement may be entirely dependent on the precise mechanism employed for storage and retrieval of data, in violation of the principle of media neutrality.

public performance of a derivative work would also constitute reproduction or performance of the original. However, Formgen authorized users to create and distribute those levels, raising the question whether Micro Star could, then, be liable to Formgen for merely triggering authorized displays. The court specifically refused to view Micro Star as the beneficiary of the users' license to create new levels and rejected the argument that Formgen had abandoned its rights by licensing users to create and distribute their own levels. Id. at 1113-14. While Formgen may have abandoned its right to create and distribute new levels, the court held, it had not abandoned its exclusive right to commercially exploit those levels. Id. It is worth noting that while rights to adapt and distribute works are among those specifically granted to the copyright owner under Section 106, a separate right to commercial exploitation is not, though Jessica Litman has suggested that a generalized right to commercial exploitation might, in fact, be a more workable formulation than the reproduction right. See 17 U.S.C. $\$ 106$ (2000); JessiCA LITMAN, DigITAL COPYRIGHT 180 (2001). Additionally, the conclusion that triggering appearance of the characters and story lines in enhanced levels constitutes infringement may be somewhat at odds not only with Galoob (because Nuke It merely provides instructions leading to the recreation of the levels), but also with the court's later decision in Sony Computer Entertainment, Inc. v. Connectix Corp., 203 F.3d 596, 53 U.S.P.Q.2d (BNA) 1705 (9th Cir. 2000), holding that creation of an software emulator which permitted users to play Sony Playstation games on their computers, instead of on Sony's console, was a permissible fair use. Connectix focused on the intermediate copying necessary to reverse engineer the console's BIOS software, rather than on enhancements of game play. See id. However, Micro Star's inference that simply triggering display of the game characters and story lines is infringement would seem to preclude the use of an emulator to literally produce game displays on a different machine.

${ }^{105}$ Micro Star, 154 F.3d at 1112.

${ }^{106}$ Loren, supra note 102, at 59. 
The reliance on finely-drawn distinctions between different storage and retrieval technologies resurfaces in different contexts in the database compilation and file sharing cases. The contributory infringement arguments appearing in Midway and Galoob, but short-circuited by the court's finding of direct infringement in Micro Star, also reappear in these later cases as the courts struggle with the relationships between copyright owners, technology providers, and end users.

\section{B. DATABASE PRODUCTS-DEFINITIONS AND TECHNOLOGICAL DETAIL}

The Supreme Court's decision in New York Times Co. v. Tasini ${ }^{107}$ is the centerpiece of this set of cases. Two circuit court cases, Matthew Bender \& Co. v. West Publisbing Co ${ }^{108}$ and Greenberg v. National Geographic Society, ${ }^{109}$ decided after the lower court opinions in Tasini but prior to the Supreme Court's decision, are also notable. Finally, the very recent opinion in Faulkner v. National Geographic Society ${ }^{10}$ interprets Tasini to produce a result somewhat at odds with Greenbeng. Tasini, Greenberg, and Faulkner involve the relative rights of authors and publishers of individual, copyrighted works compiled in collective works ${ }^{111}$ such as newspapers and magazines. Matthew Bender involves claims between competing compilation publishers.

In Tasini, freelance authors of articles published in the New York Times, Newsday, and Sports Illustrated claimed that their copyrights were infringed by the print publishers' licensing of rights to electronic publishers who included the articles in electronic databases online and on $\mathrm{CD} .{ }^{112}$ All three print publishers licensed Lexis-Nexis to reproduce and sell the articles on its NEXIS service. ${ }^{113}$ The New York Times, additionally, authorized inclusion of its issues on two CD products: the New York Times OnDisc (NYTO) and General Publications OnDisc (GPO). ${ }^{14}$ The authors received no additional compensation for these republications of their works. ${ }^{15}$

${ }^{107} 533$ U.S. 483, 59 U.S.P.Q.2d (BNA) 1801 (2003).

108158 F.3d 693, 48 U.S.P.Q.2d (BNA) 1545 (2d Cir. 1998).

${ }^{109} 244$ F.3d 1267, 58 U.S.P.Q.2d (BNA) 1267 (11 th Cir. 2001).

110294 F. Supp. 2d 523, 69 U.S.P.Q.2d (BNA) 1370 (S.D.N.Y. 2003).

111 Collective works, like anthologies and periodicals, collect a number of separate and independent works into a collective whole. The broader term "compilation" also denotes works formed by the collection of preexisting materials or of data that are selected, coordinated, or arranged in such a way that the resulting work as a whole constitutes an original work of authorship. The term "compilation" includes collective works. See 17 U.S.C. $\$ 101$. The periodicals in Tasini constituted both compilations and collective works. 533 U.S. 483.

${ }^{112}$ Tasini, 533 U.S. at $488-90$.

113 Id.

114 Id.

115 Id. 
Compilers receive copyright protection for their compilations only as to original elements such as commentaries, selection, and arrangement, which they add to the underlying works gathered in the compilation. ${ }^{116}$ Additionally, section 201(c) of the Copyright Act provides:

In the absence of an express transfer of the copyright or of any rights under it, the owner of copyright in the collective work is presumed to have acquired only the privilege of reproducing and distributing the contribution as part of that particular collective work, any revision of that collective work, and any later collective work in the same series. ${ }^{17}$

As none of the freelancers in Tasini had expressly transferred their rights, ${ }^{118}$ the statutory presumption applied and the court's opinion focused on whether the electronic republications constituted permissible revisions of the original collective works or were, instead, infringements of the freelancers' rights in their individual articles. The manner in which the electronic products stored and retrieved the articles turned out to be determinative.

NEXIS and NYTO both provided text-only information. The same electronic files used to print the text of the hard copy publications were sent to the electronic publishers, who coded them to facilitate electronic searches. ${ }^{119}$ NEXIS added them to its extensive databases, while NYTO accumulated issues of the New York Times on CDs. Both products employed familiar search-and-retrieval methods, producing displays only of individual articles, with references to source but no surrounding context from the original publication. GPO, on the other hand, was image-based, containing exact reproductions of the printed New York Times Book Review and Sunday Magazine, as well as of other publications. Searches, however, produced displays only of the pages related to the individual articles retrieved. ${ }^{120}$

116 The underlying works must be used with permission of the author or the compiler receives no copyright protection. 17 U.S.C. $\$ 103$ (2002).

11717 U.S.C. $\$ 201$ (c) (2000).

${ }^{118}$ Publisher claims that documents such as endorsed checks which served as copyright transfers did not survive the lower courts. Tasini, 533 U.S. at 489 n.1.

${ }^{119}$ Id. at 489-90.

${ }^{120}$ GPO's image-based discs were not themselves searchable but were accompanied by searchable text-based discs providing an index and abstracts of articles: Users could search the abstracts, identify articles of interest, then return to the image-based discs to retrieve the articles. See Tasini v. New York Times Co., 972 F. Supp. 804, 808-09, 43 U.S.P.Q.2d (BNA) 1801, 1804-05 (S.D.N.Y. 1997). The district court opinion provides more detail than the Supreme Court opinion regarding the workings of the various publications. 
Noting that Congress specifically designed section 201(c) to correct inequitable treatment of authors under the prior Copyright Act of 1909, ${ }^{121}$ the majority opinion found that the electronic publishers had clearly exercised the reproduction and distribution rights of the freelancers unless their activities fell within the revision privilege. ${ }^{122}$ In determining whether the electronic reproductions were revisions, the majority focused on the articles as presented to and perceived by the users, citing the statutory definitions of the terms "copies" and "fixed" with their focus on media from which works can be perceived, reproduced, or communicated. ${ }^{123}$

Since all three databases presented users with the individual articles without the surrounding context of the original periodicals, the majority opinion did not consider the electronic versions to be revisions of the original compilation. ${ }^{124}$ Rather, it viewed the retrieved articles either as individual works or, alternatively, as parts of a new collective work, the database itself. In either case, the publishers had exceeded the scope of the revision privilege and infringed the freelancers' rights to reproduction and distribution. ${ }^{125}$

The publishers specifically cited the doctrine of media neutrality, arguing that mere transfer into another medium should not affect the revision privilege. ${ }^{126}$ The majority opinion, however, distinguished conversion of intact periodicals from one medium to another from the databases' separation of the periodicals into individual articles. "[M]edia neutrality should protect the Authors' rights in the individual Articles to the extent those Articles are now presented individually, outside the collective work context, within the Databases' new media."127 Similarly, the court rejected the argument that users could manipulate the database

${ }^{121}$ Prior to enactrnent of the 1976 Copyright Act, the copyright of a contributor to a collective work was recognized only if the collective work contained a separate copyright notice in the contributor's name. Under the former doctrine of indivisibility, the author could not transfer only the limited right to reproduce and distribute in the collective publication but must transfer his copyright in its entirety. If the collective work carried only the publisher's copyright notice, the author's copyright fell into the public domain. Publishers often refused to carry separate notices, placing the author's copyright at risk, and forcing the author to transfer the entire copyright. Congress sought to remedy this imbalance of power by providing for division of the copyright into discrete rights, each of which could be separately transferred by either exclusive or nonexclusive licenses, see 17 U.S.C. $\$ 106$ (c), dispensing with the requirement for separate notices for each contributor, see 17 U.S.C. $\$ 404$ (a) (2000), and specifically limiting the compiler to the privileges established in section 201(c) absent an express transfer of rights. See Tasini, 533 U.S. at 494-97.

${ }^{122}$ Tasini, 533 U.S. at 500.

${ }^{123}$ Id. at $498-99$. The term "revision" is not defined in the statute.

${ }^{124}$ Id. at $499-501$.

${ }^{125}$ Id.

${ }^{126} \mathrm{Id}$. at 502.

${ }^{127}$ Id. 
to produce an exact replica of the original periodical, observing that the fact that a third party could manipulate the data to produce a noninfringing document did not absolve the publishers from infringement. ${ }^{128}$ Nor did Sony's staple article of commerce doctrine shelter them from claims of infringement since the publishers did not merely supply enabling technology to their users, but directly infringed by creating and distributing actual copies themselves. ${ }^{129}$

The majority opinion viewed the electronic files captured on the databases as copies fixed in a tangible medium of expression ${ }^{130}$ and their presentation to users as a distribution of copies of individual articles. Justice Stevens' dissent, on the other hand, started from the intermediate batches periodically transferred by the print publishers to the electronic publishers rather than from the content as stored on the database or ultimately presented to database users.

The dissent analyzed three separate steps: the conversion from print to electronic format, the transfer of electronic files, and the incorporation of the files into the database. ${ }^{131}$ Justice Stevens found that the text files created by the print publishers for NEXIS and NYTO constituted revisions of each affected issue of the publication. ${ }^{132}$ Citing the principle of media neutrality, he argued that conversion of the collective works into separate electronic files merely reflected the different nature of the electronic medium, which required that the works be broken down into smaller, less memory-intensive units. ${ }^{133}$ Justice Stevens accused the majority of backing away from media neutrality by requiring that articles appear in context. ${ }^{134}$ In essence, his approach would require that any changes dictated by change of medium should not count toward infringement under the media neutrality principle.

128 Id. at 504.

${ }^{129}$ Id.

${ }^{130}$ The majority opinion observed that Lexis's central discs and the CD products themselves reproduced copies of the articles. See id. at 498.

${ }^{131}$ Id. at 511. See infra Part IV, observing that, in fact, the content was not converted from print to electronic format, but existed electronically prior to either print or electronic publication.

${ }^{132}$ Id. at $512-14$.

${ }^{133}$ Id. at 514 n.11. The majority opinion correctly observed that while this may be true, the separation into individual files also reflected the economic market. Id. at $502 \mathrm{n} .11$. The dissent noted that the New York Times certainly could "reprint its issues in Braille, in a foreign language, or in microform [and any resulting] differences would ... largely result from the different mediums being employed." Id. at 512-13. Justice Stevens' references to translations into foreign languages and Braille, which are not physical media, but are modes of expression, indicate that he viewed media neutrality as encompassing more than mere indifference to physical storage media. See id. at 512-13. Translation to Braille would both create a derivative work (translation to a different language) and transfer the work to a new physical medium (raised bumps on paper).

${ }^{134}$ Id. at $512-15$. 
In his view, if the electronic files constituted revisions, the mere transfer and commingling of those files with other materials in the electronic publishers' databases should not change that result any more than would the placement of a single edition of the New York Times in a physical library, since each individual article reminded the reader that it was part of a collective whole. ${ }^{135}$ The publishers could not, therefore, be guilty of direct infringement and, if their users chose to infringe, the publishers should be protected under Sony from contributory liability. ${ }^{136}$

In both Tasini opinions, the close readings of the statutory term "revision" recall the definitional approach in White-Smith, while the detailed descriptions of electronic systems resemble those in Micro Star. Both opinions rely extensively on analogies to microform and library collections of multiple issues of the same work, recognizing that such collections appear to constitute permissible revisions but reaching opposite conclusions as to the lessons to be taken from these analogies. ${ }^{137}$

The majority focuses so exclusively on the particular technologies at hand that it provides little guidance as to what kind of electronic version, if any, would qualify as a revision. It is not entirely clear how much context must be reproduced or whether periodical issues (compilations in themselves) can be cumulated though the references, in dicta, to microforms may indicate that such cumulation is acceptable. ${ }^{138}$ To date, two opinions involving the same electronic collections of issues of National Geographic magazine have reached conflicting results.

Greenberg v. National Geographic Society, ${ }_{139}^{139}$ an Eleventh Circuit opinion rendered before the Supreme Court's decision in Tasini, rejected a revision right claim for an image-based CD library of issues of the National Geographic magazine which preserved full context. ${ }^{140}$ The Greenberg court held that transformation to an

${ }^{135}$ Id. at $516-17$.

${ }^{136}$ Id. at 518.

${ }^{137}$ Because microforms reproduce images of the complete issues, the majority uses the analogy to bolster its view that articles produced without full context are not revisions. Id. at 501-02. The dissent uses the microform analogy to suggest that collection of multiple issues is well-accepted and that presentation of individual articles is necessitated only by medium change. See $i d$. at 512-13. Consequently, a media neutral ruling should not distinguish between the microforms and databases as acceptable revisions. Id.

${ }^{138}$ If not, even a microform accumulating editions of a publication would not constitute a revision, and it is difficult to imagine any economically viable electronic version of a print publication that would qualify. See Amir A. Naini, Note, New York Times Co. v. Tasini, 17 BERKELEY TECH. L.J. 9, 21, 22 (2002).

139 244 F.3d 1267.

${ }^{140}$ Greenberg was a freelance photographer whose work appeared in several issues of National Geographic magazine. He retained the copyright in his photographs. The collection not only replicated his photos, but used one in a new "moving covers" sequence, which the court separately 
electronic medium and addition of an introductory sequence and search and retrieval software created an entirely new product for a new market. This product was a new collective work, not a revision. The addition of the introductory sequence, which created an unauthorized derivative of one of the plaintiffs photographs, distinguishes the case from Tasini. However, the Greenbery court raised the possibility, in dictum, that mere addition of independently copyrightable material such as software might be sufficient to create a new collective work. ${ }^{141}$

In Faulkner v. National Geographic Society, ${ }^{142}$ the court addressed nearly identical claims brought by freelance contributors and roundly rejected the Greenberg decision in light of Tasini. ${ }^{143}$ The Faulkner court read the legislative history as contrary to the Greenberg view that mere addition of new material to a collection of issues of the same publication was inconsistent with the revision privilege. ${ }^{144}$ Focusing on Tasini's requirement of presentation in context, the lower court interpreted the Supreme Court's discussion of microform as an indirect blessing for collections of issues of the same periodical presented in full context. ${ }^{145}$ Since the National Geographic products were based on scanned images of the original publications and presented the issues to the user in full context, the court held them to be permissible revisions of the original magazines. ${ }^{146}$

found to be an infringing derivative work. $I d$. at 1274 . The CD library permitted the user to print out the image of any page of the magazine, but did not allow the user to separate the photographs from the text or to edit the pages in any way. Id. at 1269 .

${ }^{141} I d$. at 1273. The court observed that the replica of the archived issues was unusable without the addition of the program permitting search and retrieval, itself a copyrightable work. The court raised, but did not decide in the context of the case, the question whether addition of software to a work, standing alone, would create a new collective work. Id. at 1273 n.12. One commentator observes that, if the addition of software to content inevitably creates a new collective work, much of the Tasini majority's opinion, with its insistence on context, would be entirely superfluous since the operation of the databases inevitably required software in addition to the original content of the publications. See Jennifer L. Livingston, Note, Digital "Revision": Greenberg v. National Geographic Society, 70 U. CIN. L. REV. 1419, 1437 (2002).

142294 F. Supp. $2 d 523$.

${ }^{143}$ The plaintiffs were freelance photographers or writers who created images or text that originally appeared in the print version of the National Geographic Magazine. They alleged that unpaid use of their works in an electronic collection of multiple issues of the magazine-the Complete National Geographic collection also challenged in Greenberg - violated their copyrights. None of the plaintiffs' works appeared in the introductory sequence, as did Greenberg's work, so their claim was based entirely on translation of the collected magazine issues to electronic format. Id. at 525-26. The court found that the defendants were not collaterally estopped by the Greenberg decision because the intervening decision in Tasini changed the applicable legal doctrine. Id. at 537-38.

144 Id. at 539.

${ }^{145} I d$. at 541.

${ }^{146}$ Id. at $540-43$. 
The court further rejected the plaintiffs' argument, based on Greenberg, that the electronic works were entirely new works for a new market, and therefore not revisions, observing that all revisions are new products and mere change of medium is irrelevant "as media neutrality is a fundamental principle of the Copyright Act." 147 The court interpreted Tasini to require that freelancers be protected only where there is demand for a freestanding article or a "new collection" rather than a revision. ${ }^{148}$ While the Faulkner interpretation may accord with the Supreme Court's dictum regarding microform reproductions, it runs against the underlying policy argument, based on the legislative history, favoring fair payment to freelancers. Like its predecessor opinions, Faulkner relies primarily on technological distinctions to support its result.

In a different context, the Second Circuit took a somewhat more balanced approach to database compilations in Matthew Bender ơ Co., Inc. v. West Publisbing $\mathrm{Co}^{149}$ Nonetheless, its judgment rests primarily on technical interpretation of the statutory definitions of copies and fixation. Unlike Tasini, Matthew Bender dealt directly with claims of secondary liability for infringement by electronic products of competing publishers. But like the Tasini majority, the Matthew Bender court focused on the information as presented to users by a search-and-retrieval system.

West claimed that its selection and arrangement of its case reporters was infringed by competitors' use of star pagination ${ }^{150}$ in case reports contained on CD products. ${ }^{151}$ West argued that the CDs were infringing copies because users might, for entirely unimaginable reasons, utilize the page break information to recreate West's reporters, making the competitors contributory infringers. ${ }^{152}$ The only arguably protected element of West's reporters was its arrangement of the individual case reports in each reporter. ${ }^{153}$ Matthew Bender's CDs, and those of an intervenor, Hyperlaw, contained considerable information in addition to the

147 Id. at 541.

148 Id. at 542.

149158 F.3d 693, 48 U.S.P.Q.2d (BNA) 1545 (2d Cir. 1998).

${ }^{150}$ Star pagination reveals every page break in the report so that users can correctly cite to the location of particular text.

151 Matthew Bender, 158 F.3d at 700-02.

${ }^{152}$ Id. West's claim was complicated by the fact that it had previously admitted that use of the beginning page number of each case was fair use. See id. The court was not convinced that mere addition of the page break numbering transformed a fair use into an infringement. See id.

153 The page numbers themselves, inserted automatically in the printing process, were insufficiently original or creative to receive copyright protection. Id. at 699. Interestingly, the court observed in a footnote that the same result would be reached using a medium-based argument. Id. at $699 \mathrm{n} .9$. Intangible works, the court said, are protected only when fixed in a tangible medium of expression, but that does not mean that elements of a particular medium, like pagination, which are not themselves part of the intangible work, receive protection. Id. 
contested case reports and were arranged differently. ${ }^{154}$ The search and retrieval system listed and displayed individual case reports only. Since the CDs did not fix West's particular selection and arrangement in their databases or make them perceptible to users, the court held they did not create actionable copies of West's reporters. ${ }^{155}$ The mere possibility that users might rearrange the case opinions as presented to them by Matthew Bender was not sufficient excuse for enjoining a manifestly useful service under Sony's staple article of commerce doctrine. ${ }^{156}$

The court specifically discussed media neutrality, finding that West's redefinition of the term "copy" to include potential rearrangements by users in the electronic context would run contrary to the principle of media neutrality. ${ }^{157}$ Unlike the court in Greenberg, the Matthew Bender court engaged in a more thorough discussion of underlying policy issues. ${ }^{158}$ Nonetheless, its judgment ultimately rests, like the judgment in White-Smith, on its technology-based determination of what is or is not a copy, thereby avoiding the rather more interesting question whether West's arrangement is sufficiently original to be protected at all. ${ }^{159}$

In all of the database cases, the courts' judgments depend in large part on close readings of statutory definitions applied to the specific workings of storage and retrieval technologies, with a focus on the manner in which the systems present data to users. Tasini, in particular, draws a technology-based line between analog compilations and their electronic counterparts based on their different functionalities. The majority and dissent diverge entirely in their interpretations of the meaning of media neutrality as well as their applications of the principle in context.

The Sony theme of allocation of liability between technology providers and users runs like an undercurrent through the Tasini opinion, but surfaces rarely

154 West state reporters are arranged by region, state, chronology, and court (with variations in different reporter series). Matthew Bender's CDs contained only New York opinions in chronological order and added statutory and secondary materials. Hyperlaw's CDs also added many cases not published by West, in roughly chronological order. Id. at 697-98. Because of the additional materials in both CDs, infringement of West's selection was not a serious issue.

${ }^{155}$ Id. at $700-02$.

156 Id.

157 Id. at $702-04$.

${ }^{158}$ The court discusses generally the importance of the originality requirement, the failings of the defunct "sweat of the brow" school of copyright protection, and the inadvisability of allowing West to leverage control of pagination into control of the public domain information contained in its reporters. Id. at $702-04$.

${ }^{159}$ Consequently, the court's analysis, like Tasini's, leaves some unanswered questions since, by inference, a CD which could be directly read by a device which renders a protected arrangement perceptible without user intervention would infringe on West's arrangement. See Deborah Tussey, The Creative as Enemy of the True: The Meaning of Originality in the Matthew Bender Cases, 5 RICH. J.L. \& TECH. 10, para. 44, 45 (1999). 
given the majority's determination that the publishers directly infringed. The issue takes center stage, however, in the peer-to-peer file sharing cases. In Napster, the Ninth Circuit faced the issue directly and again produced a technology-centered judgment. ${ }^{160}$ Napster would probably have lost under any circumstances, but under the court's analysis, it most clearly lost because it used a central server.

\section{PEER-TO-PEER FILE SHARING—WRITING TECHNOLOGY INTO THE RULES}

While Napster raises many issues, I concentrate here on the architectural aspects of the case. Napster has now been succeeded by two similar cases, In re Aimster Copyright Litigation ${ }^{161}$ and Metro-Golduyn-Mayer Studios, Inc. v. Grokster, Ltd., ${ }^{162}$ the latter of which demonstrates the impact of Napster's technology-centered analysis. The Aimster decision, while imperfect, demonstrates a more medianeutral, balanced approach.

Napster was the first popular peer-to-peer file sharing system. The service provided its registered users with software and continuing services ${ }^{163}$ which permitted them to exchange music files in "MP3" format ${ }^{164}$ over the Internet, thereby facilitating widespread infringement of copyrighted works. Napster managed these functions through a centralized server system which, critically, gave Napster the ability to block certain users and remove infringing material; Napster itself never copied or distributed music files nor did it serve as a conduit for file transfer by its users. ${ }^{165}$ Napster's situation was thus distinguishable from that of MP3.com, which had previously been found liable for direct infringement because it actively copied a library of CDs into MP3 format and served them up to its online subscribers. ${ }^{166}$ That Napster users did engage in direct infringement

160239 F.3d 1004.

161334 F.3d 643, 67 U.S.P.Q.2d (BNA) 1233 (7th Cir. 2003).

162259 F. Supp. 2d 1029, 66 U.S.P.Q.2d (BNA) 1579 (C.D. Cal. 2003) [hereinafter Grotester I], affd, 380 F.3d 1154, 72 U.S.P.Q.2d (BNA) 1244 (9th Cir. 2004) [hereinafter Grokster II], cert. granted, 125 S. Ct. 686 (2004).

${ }^{163}$ Napster supplemented its "MusicShare" software with a user directory, a searchable index of available titles, a hotlist function, and chat tooms. Napster also provided the Internet addresses necessary for users to contact each other and exchange files. See Napster, 239 F.3d at 1012.

${ }^{164}$ MP3 (short for MPEG-3) is a digital file format. "Ripping" software compresses audio data from a $C D$ onto the user's hard drive, facilitating subsequent transfer through email or any file transfer protocol. See id. at 1011. Compression using MP3 technology marginally reduces sound quality, but the reduction is undetectable by most listeners.

${ }^{165}$ Id. at 1011-23, 1024.

166 See UMG Recordings, Inc. v. MP3.com, Inc., 92 F. Supp. 2d 349, 54 U.S.P.Q.2d (BNA) 1668 (S.D.N.Y. 2000). 
was undisputed on appeal; ${ }^{167}$ the court's inquiry focused on Napster's secondary liability.

Under the traditional test, a contributory infringer is one who knows or has reason to know of its users' infringements and induces, causes, or materially contributes to them. ${ }^{168}$ Under Sony's staple article of commerce doctrine, the court must additionally determine whether the defendant's product is capable of substantial noninfringing uses that might immunize it from liability, striking a balance between the copyright holder's legal monopoly and the rights of others to engage in unrelated areas of commerce. ${ }^{169}$ Establishment of a fair use defense supports the existence of a substantial noninfringing use. ${ }^{170}$ The Ninth Circuit found that the staple article of commerce doctrine was relevant only to the contributory infringement claim, reading the Supreme Court's uses of the term vicarious liability in Sony as generic references to secondary forms of liability. ${ }^{171}$

The appellate court corrected the lower court's holding that Napster had no substantial noninfringing uses, finding that the district court gave insufficient consideration to potential, as opposed to actual, noninfringing uses. ${ }^{172}$ Reading Sony only in relation to the knowledge requirement for contributory infringement, the court held that the requisite level of knowledge could not be imputed to Napster merely because its architecture permitted infringement if the system also had existing or potential commercially significant noninfringing uses. ${ }^{173}$ The court found itself "compelled to make a clear distinction between the architecture of the Napster system and Napster's conduct in relation to the operational capacity of the system."174 In a somewhat murky passage, the court observed that if a computer system operator learns of specific infringing material available on its system and fails to purge such material, the operator knows of and contributes to direct infringement. ${ }^{175}$ Since Napster did have actual knowledge of specific infringing material on its system, ${ }^{176}$ could have blocked access to the system by

167 Napster, 239 F.3d at 1013.

${ }^{168}$ Id. at 1019-20 (citing Gershwin Publ'g Corp. v. Columbia Artists Mgmt., Inc., 443 F.2d 1159, 1162, 170 U.S.P.Q. (BNA) 182, 184-85 (2d Cir. 1971)); see also Fonovisa, Inc. v. Cherry Auction, Inc., 76 F.3d 259, 264, 37 U.S.P.Q.2d (BNA) 1590, 1594 (9th Cir. 1996).

${ }^{169}$ See Sony, 464 U.S. at 442.

170 Id.

171 Napster, 239 F.3d at $1022-23$.

${ }^{172}$ Id. at 1021.

${ }^{173}$ Id. at 120-21. Sony found no precedent for basing vicarious liability on constructive knowledge that users of a copying device might infringe, where the device also had noninfringing uses. Sony, 464 U.S. at 439.

${ }^{174}$ Napster, 239 F.3d at 1020.

175 Id. at 1021-22.

176 The circuit court placed the burden on the music industry to notify Napster that specific infringing material was being exchanged by its users and found, on the facts of the case, that Napster 
suppliers of the infringing material, and failed to purge the material, it was contributorily liable notwithstanding Sony's staple article of commerce doctrine. ${ }^{177}$

With respect to the requirement of material contribution, the court relied on its earlier precedent holding a swap meet organizer responsible for infringement by vendors. ${ }^{178}$ The court found that users could not easily engage in infringing file sharing without Napster's services and Napster's central servers provided the "site and facilities" for, and materially contributed to, their infringements. ${ }^{179}$ Consequently, Sony offered no shelter against contributory liability. ${ }^{180}$

Vicarious liability requires a showing that the defendant has the right and ability to supervise the infringing activity and benefits financially from it. ${ }^{181}$ In Napster, the court found financial benefit based on evidence showing that, even though Napster did not charge for its services, the increased user base resulting from infringement was essential to its future profitability. ${ }^{182}$ Its centralized architecture was, again, determinative of its duty to police its users. Napster specifically retained the right to control access to its system and, through its servers, could both block certain users and remove infringing materials, demonstrably possessing the right and ability to supervise its "premises." 183 The court did observe that Napster's duty to police its premises was not unlimited, but was "cabined by the system's current architecture."184 The system could not read the content of indexed files, other than to check that they were in the proper MP3 format, but, once notified of infringement, Napster could have used its indexing function to find and remove offending material and failed to do so. ${ }^{185}$ Consequently, Napster was vicariously liable. ${ }^{186}$

The court rejected Napster's claim that its users were engaged in fair use, under Sony, because they used the service for substantial noninfringing uses such as permissive use of recordings by some artists, ${ }^{187}$ sampling music prior to purchase, and space-shifting by accessing works in MP3 format that they already

had actual knowledge of its users' infringements. Id. at 1020-22.

${ }^{177}$ Id.

${ }^{178}$ See Fonovisa, 76 F.3d at 264 (holding a swap meet organizer contributorily and vicariously liable for the distribution of infringing recordings by participants).

179 Napster, 239 F.3d at 1022.

${ }^{180} I d$. at $1020-22$.

${ }^{181} I d$. at 1022.

182 Id. at 1023.

${ }^{183}$ Id.

${ }^{184}$ Id.

${ }^{185}$ Id.

${ }^{186}$ Id.

${ }^{187}$ Id. at 1019 . The court readily dismissed this claim since the plaintiffs made no attempt to enjoin permissive distribution. 
owned in $\mathrm{CD}$ format, ${ }^{188}$ which the Ninth Circuit approved in Recording Industry Ass'n of American v. Diamond Multimedia Systems, Inc. ${ }^{189}$ Emphasizing the harm to plaintiffs' present and future markets for online music distribution, the court found that all four fair use factors weighed against Napster. ${ }^{190}$ Sony and Diamond were inapposite, the court held, because the methods of shifting approved therein did not also simultaneously involve distribution of the copyrighted material to the general public, but exposed the material only to the original user. ${ }^{191}$

The Ninth Circuit required that the district court's preliminary injunction be narrowed on remand, but affirmed its issuance. ${ }^{192}$ Ultimately the district court, as part of its injunction against and subsequent monitoring of Napster, imposed a partially architectural remedy: the use of filtering software to block infringing materials. ${ }^{193}$ The functional inadequacies of that solution and Napster's consequent inability to comply with the court's zero tolerance policy eventually resulted in shutdown of the service. ${ }^{194}$

The Napster opinion targets two key elements: the peer-to-peer provider's actual knowledge of specific infringements by users and its structural ability to control them. While the appellate ruling appropriately narrowed the impact of the district court's ruling, it did so by relying heavily on Napster's particular architecture, seemingly reading Napster's functional limitations into the knowledge requirement for contributory liability by requiring actual knowledge of specific acts as well as the ability to block infringing material. Perhaps more importantly, it gives greater weight to its interpretation of the knowledge

188 Id. at 1014.

189180 F.3d 1072, 51 U.S.P.Q.2d (BNA) 1115 (9th Cir. 1999). Space-shifting is an extension of Sony's time-shifting rationale. The Diamond court found that the Rio MP3 player, a transportable device which stored and played back music files downloaded from users' hard drives, had a substantial non-infringing use, space-shifting lawfully obtained works so they could be enjoyed in different locations. Diamond was decided under the Audio Home Recording Act (AHRA), 17 U.S.C. $\$ 1001-1008$, not the 1976 Copyright Act. The Napster court separately rejected claims that Napster was sheltered by safe harbors under the AHRA (for home audio taping) and the Digital Millennium Copyright Act (for online service providers). See Napster, 239 F.3d at 1024, 1025.

190 Napster, 239 F.3d at 1014-19.

191 Id. at 1019.

192 Id. at 1029.

193 See A\&M Records, Inc. v. Napster, Inc., No. C99-05138 MHP, C00-1369 MPH, 2001 WL 227083 (N.D. Cal. 2001).

194 As directed by the court of appeals, the district court also required the recording industry to notify Napster of specific infringements. See A\&M Records, Inc. v. Napster, 284 F.3d 1091 (9th Cir. 2002) (approving the district court's modification of its preliminary injunction to impose the filtering requirement and, when compliance proved less than perfect, to shut Napster down). Napster has now been resurrected as a paid, and royalty-paying, subscription service. See http://www.napster. com (last visited Apr. 3, 2005). 
requirement than it does to its fair use analysis, undermining Sony's emphasis on balancing incentives against innovation. ${ }^{195}$

By relying so heavily on system architecture, the court issued an open invitation to the burgeoning peer-to-peer industry to design systems that negated one or both of the requirements for secondary liability. The industry met the challenge with alacrity by shifting to decentralized peer-to-peer systems such as Gnutella and its successors. ${ }^{196}$ Some providers also adopted the use of encryption to shield user transactions not only from copyright owners, but from the providers themselves, in hopes of avoiding the knowledge required for contributory infringement. ${ }^{197}$

These next-generation file sharing systems, specifically designed to avoid Napster's fate, were challenged by copyright owners in Grokster $I^{198}$ The defendants, Grokster and Streamcast, distributed two different kinds of file sharing software. Both platforms provided connection to a peer-to-peer network, lists of online users and available files, communication with other users, and features for organizing and playing the shared files. Neither allowed its distributor to control the file sharing network. ${ }^{199}$ The district court did its best to apply

195 But see In re Aimster Copyright Litigation, 334 F.3d 643, 649, 67 U.S.P.Q.2d (BNA) 1233, 1237 (7th Cir. 2003), rejecting this approach. Goldstein observes that the purposes of the knowledge requirement and of the substantial, noninfringing use requirement are different and that Napster's emphasis undermines Sony's purpose to prevent the effective extension of copyright monopolies over unrelated consumer goods or devices. 2 PAUL GOLDSTEIN, COPYRIGHT \$ 6.1.2, ๆ 6:12-1 (2d ed. 2003).

196 The earliest decentralized file sharing system, Gnutella, was so radically decentralized that it suffered from stability and performance problems. Gnutella was soon succeeded by improved versions, as well as by the FastTrack protocol and its client application Kazaa. Unlike Gnutella, which is an open source protocol, FastTrack was licensed out to companies like Grokster and rapidly became the most successful file sharing protocol after the demise of Napster. Unlike Gnutella, FastTrack centralizes certain functions, such as user registration and logins, but, like Gnutella, it separates the communication protocol from the client software so that services like Grokster have no ability to regulate or shut down the peer-to-peer network. See Wu, supra note 55, at 730-37 for a summary of the development of decentralized peer-to-peer systems.

197 See infra text accompanying notes 219-37; see also Braw/Over File-swapping Spawns 'Secure' Softwan, SILICONVALLEY.COM, July 24, 2003, at http://www.siliconvalley.com/mld/siliconvalley/news/ editorial/6374384.htm (last visited Apr. 3, 2005), reporting that, in response to suits by the recording industry against peer-to-peer users, software providers upgraded their programs to protect users' privacy by masking their identities from Recording Industry Association of America (RIAA) sleuths.

198259 F. Supp. $2 \mathrm{~d} 1029$. The plaintiffs in two consolidated cases represented the motion picture and recording industries, music publishers, and songwriters. Id. at 1031-32. The defendants were three distributors of file sharing software-Grokster, Streamcast Networks, and Kazaa-although Kazaa was not a party to the motions for summary judgment addressed in the case. See id.

199 Grokster distributed a branded version of the Kazaa Media Desktop based on FastTrack while Streamcast offered its own proprietary software, Morpheus, based on the open-source Gnutella protocol. Id. at 1032-33. Grokster's system was not centralized, but operated through a variable 
Napster's enhanced standard for contributory liability, producing an interpretation that was in accord with the Ninth Circuit's interpretation of the legal standards, but, entirely because of technological differences in the file sharing systems, exonerated the defendants from any contributory or vicarious liability. ${ }^{200}$

Regarding the contributory infringement claim, the court found significant evidence of substantial noninfringing use to share non-copyrighted or permissive material. ${ }^{201}$ Consequently, under Napster's interpretation of Sony, defendants must have actual knowledge of specific infringements at a time when they also materially contributed to the infringement and had the ability to stop it. ${ }^{202}$

The architecture of the two systems proved determinative. The court found a "seminal distinction" between the decentralized systems and Napster. ${ }^{203}$ While the defendants had general knowledge of their users' infringements, they did not have actual knowledge of specific infringements and did not facilitate the exchange of files between users in the way Napster did. ${ }^{204}$ In fact, if either defendant shut down, users of their products could continue sharing files with little or no interruption. ${ }^{205}$ Analogizing the defendants' software to the home VCR or the photocopier, the court held that routine technical assistance to and the ability to communicate with users were not sufficiently substantial to constitute material contribution to the alleged infringement. ${ }^{206}$

With regard to the claim of vicarious infringement, the court found financial benefit based on increased subscriber bases and advertising revenues, but the architecture defeated the plaintiffs' attempts to prove that defendants' had the right and ability to control user activities. ${ }^{207}$ Napster, the court observed, offered

series of "supernodes"- users' computers with temporarily heightened functionality. A user's node might be a supernode one day and not the next, depending on resource needs and availability of the network. "Root" supernodes directed users to active supernodes. Grokster itself did not control a supernode, nor were its computers involved in any way in file transfers-the service simply provided users with a start page and pushed advertising. Morpheus was even more decentralized than Grokster's FastTrack-based system. Users of the software contacted publicly available directories of online users, none of them operated by Streamcast, and passed search requests from user to user until a match was found. Id. at 1039-41. Since the plaintiffs' sought preliminary injunctive relief, the court addressed only the defendants' current systems, not claims that they had previously operated supernodes or centralized systems. Id. at 1033.

${ }^{200}$ See id.

201 Streamcast produced evidence regarding distribution of movie trailers, free sample songs, public domain works, permissive distribution, and free software. See id. at 1034-35.

202 See id. at 1036-37.

${ }^{203}$ Id. at 1041.

204 Id. at 1041-43.

205 Id. at 1041.

${ }^{206} I d$. at 1042-43.

207 See id. at 1043-46. 
an integrated system of software and hardware, controlling its own network. ${ }^{208}$ Here, however, defendants provided software that communicated across networks entirely outside their control. ${ }^{209}$ Rejecting the plaintiffs' argument that the software should be redesigned to filter out offending materials, the court observed that vicarious liability did not extend so far as to make providers responsible for product redesign in the absence of any showing that they had control over users. ${ }^{210}$

While the district court recognized the probability that the defendants intentionally designed around the requirements for secondary liability, it declined to expand existing copyright law in the absence of legislative guidance, citing Sony's policy of caution when confronted with innovative technologies not anticipated by Congress. ${ }^{211}$ The Ninth Circuit granted expedited review of the Grokster I decision ${ }^{212}$ and, somewhat surprisingly in light of the consequences, strongly affirmed both the Napster interpretation of contributory and vicarious infringement and the district court's application of it to decentralized services. ${ }^{213}$ The court found the systems capable of substantial noninfringing uses, such as direct artist-to-user distribution and distribution of public domain works, observing that even ten percent usage for non-infringing activities represented hundreds of thousands of legitimate transactions. ${ }^{214}$ Consequently, the court held, the plaintiffs must show that the defendants had knowledge of specific infringements at a time when they could control their users' activities and went on to say, "[i]n the context of this case, the software design is of great import." ${ }^{\prime 215}$ The absence of a central server or any control by defendants of index files precluded satisfaction of either the knowledge or material contribution elements of contributory infringement. ${ }^{216}$ The defendants could not be said, given the architecture of their systems, to offer the "site and facilities" for infringement. ${ }^{217}$ For purposes of vicarious liability, the defendants did not possess the technological control necesssary to block users from the networks. ${ }^{218}$ In the Ninth Circuit, centralized and decentralized filesharing systems receive differing treatment under

${ }^{208}$ Id. at 1038.

${ }^{209}$ Id. at $1044-45$.

210 Id. at $1045-46$.

211 Id. at 1046.

${ }^{212}$ See Appeals Court to Expedite Review of File sharing Suit, SiliconValley.com, July 17, 2003, at http://www.siliconvalley.com/mld/siliconvalley/news/editorial/6327134.htm (last visited Apr. 18, 2005).

${ }^{213}$ Grokster II, 380 F.3d at 1155.

$214 \mathrm{Id}$. at 1162.

215 Id. at 1163.

${ }^{216}$ See id.

${ }^{217}$ Id. at 1163.

${ }^{218}$ Id. 
copyright law, in apparent contravention of the principle of media neutrality, to which the court makes no reference whatsoever.

The Aimster decision, ${ }^{219}$ written by Judge Posner, offers a useful counterpoint to Napster and Grokster II. Aimster allowed users to exchange music files through instant messaging services. Like Napster, Aimster utilized a central server. All communications over the service were encrypted using software provided by Aimster in what the court obviously viewed as a deliberate attempt to shield Aimster's operators from the knowledge required for contributory liability. ${ }^{220}$ The court likened the service to a stock exchange, offering a facility for matching offers, rather than a repository of the things being exchanged, but noted that, unlike stock transactions, music file exchanges did not take place in the facility, that is, in Aimster's server. ${ }^{221}$

In an opinion centered on its interpretation of Sony, the court attempted to steer a middle course between extreme claims from both parties: that a single infringement created secondary liability, on the one hand, or that a single noninfringing use immunized against it, on the other. ${ }^{222}$ The court recognized that instant messaging services might be used for noninfringing purposes. ${ }^{223}$ While agreeing with the recording industry's argument that providers of services, unlike sellers of devices, retained an ability to control their customers' activities which must be considered in the infringement analysis, the court rejected the industry's claim that ability to control was determinative. ${ }^{224}$ If the detection and prevention of the infringing uses would be highly burdensome to a service with substantial noninfringing uses, the plaintiffs' interpretation could result in the shutting down of the service or its annexation by the copyright owners, contrary to policies established in Sony. The court specifically rejected the Napster court's holding that a facilitator's actual knowledge of specific infringing uses is a sufficient condition for contributory infringement, citing Sony's refusal to protect copyright owners against new technologies at the price of denying that technology to noninfringing consumers. ${ }^{225}$

219 In re Aimster, 334 F.3d 643.

${ }^{220}$ The Aimster system consisted of proprietary software downloaded free from its Web site, a central server, computerized tutorials, and "Club Aimster," a subscription service which made it easier for users to download the most popular music files more easily than by using the basic, free service. The central server hosted Aimster's Web site, indexed user information, and provided search and retrieval capabilities allowing users to find and exchange files: It did not copy the swapped files. Aimster users could share files only when online and connected in a chat room enabled by an instant-messaging service. Id. at 646-47.

221 Id. at 647.

222 See id. at 651.

${ }^{223}$ Id. at 647.

${ }^{224}$ Id. at 648 .

${ }^{225} I d$. at $648-49$. 
Crafting a more nuanced approach to contributory infringement, the court observed that when a product or service has demonstrable, substantial, noninfringing as well as infringing uses, courts must balance the respective magnitudes of the uses, considering both actual and potential uses. ${ }^{226}$ The mere potential for some noninfringing use is not sufficient to defeat contributory liability, but neither is anything more than a mere showing of infringing use sufficient to negate the Sony defense. ${ }^{227}$ The plaintiffs' evidence amply supported infringing uses, shifting the burden to Aimster to establish actual or potential noninfringing uses. ${ }^{228}$ Alas for Aimster, it had produced no evidence at all of noninfringing use by its customers. ${ }^{229}$ The court held that, even where there are both infringing and noninfringing uses of a service, the provider of the service must show that it would have been disproportionately costly to eliminate or at least reduce substantially the infringing uses in order to avoid liability as a contributory infringer. ${ }^{230}$ This reading imposes a significantly tougher standard than the mere capability of substantial noninfringing use mentioned in Sony. ${ }^{231}$

Nor was the court impressed by Aimster's argument that its encryption feature protected it from the requisite knowledge of specific infringing acts. Willful blindness, the court observed, is knowledge in copyright law, where even reason to know may be sufficient for liability. ${ }^{232}$ "Aimster blinded itself in the hope that by doing so it might come within the rule of the Sony decision."233 Overall, the balance weighed in favor of contributory liability.

226 See id. at 650.

${ }^{227}$ The court observed that the Sony majority was well aware, for example, that up to $25 \%$ of VCR users were infringing by fast-forwarding through commercials, but nonetheless found Sony not liable for contributory infringement. $I d$. at 649 .

${ }^{228}$ Id. at 652.

${ }^{229}$ Id. at 649-53. The court suggested several arguably noninfringing uses for Aimster, including space-shifting and exchanges of non-copyrighted information, but observed that Aimster failed to produce evidence of any such activities on its service, much less of their frequency relative to infringing uses.

${ }^{230}$ Id. at 653.

231 See Dogan, supra note 58 , at 953 n.82 (detailing the wide variations in the courts' interpretation of the substantial noninfringing use standard). They include requirements for mere capability of noninfringing use, commercially significant noninfringing use, and negative requirements that the technology not be primarily used for infringement. The confusion stems from Sony itself. Dogan advocates a context-specific approach intended to protect only consumers' access to technologies whose development would be justified by noninfringing uses. Id. at 942,943 . The Ninth Circuit, in Grokster II, specifically rejected Posner's probability analysis as well as his criticism of Napster's reading of the knowledge requirement. Grokster II, 380 F.3d at 1162 n.9.

${ }^{232}$ Aimster, 334 F.3d at 650.

${ }^{233}$ Id. at 653. 
Having found Aimster contributorily liable, the court was not required to decide the question of vicarious liability. ${ }^{234}$ In a troubling bit of dicta, the court noted that the doctrine could have been applied in Sony on the theory that Sony could have reduced the likelihood of infringement by a design change. ${ }^{235}$ Similarly, Aimster could have designed its system to limit infringement by avoiding the encryption feature and monitoring its system. ${ }^{236}$ To the extent that this passage seems to open the door to a requirement that technologies be designed to avoid copyright infringement, it clearly diverges from Sony. Aimster apparently emboldened the plaintiffs in the Grokster appeal to make a similar claim, which the Ninth Circuit rejected. In a somewhat circuitous passage, the court appeared to tie the duty to alter software to prevent infringement to a prior finding of liability for vicarious infringement. ${ }^{237}$

While giving file sharing technology due attention, the Aimster court resisted the proclivity toward technology-centered results so evident in the Napster and Grokster II decisions. The opinion centers instead on the most appropriate way to implement fundamental copyright policies, particularly the balancing of the benefits of copyright incentives against those of technological innovation in unrelated markets. The court's analysis focuses on the content exchanged on Aimster, not on the mechanics of its delivery. The Aimster decision offers a glimpse of a more media-neutral analysis which courts might employ to avoid the disparate judicial treatment of similar technologies which inevitably creates new issues for resolution by the courts or Congress.

\section{The Disadvantages of TEChNOLOgY-CENTRIC DeCisionMaKing}

In this part, I discuss several flaws in the courts' analyses in the key technology-centered cases-Micro Star, Tasini, and Napster-and raise related questions concerning the level of the courts' understanding of the technologies involved. These cases demonstrate the disadvantages of technology-centered decisionmaking, which might be remedied by a more media-neutral analysis.

234 See id.

235 Sony's relevance to vicarious liability claims may be questioned. The Napster court, for example, asserted that Sony was irrelevant to the vicarious liability claim. A\&M Records, Inc. v. Napster, Inc., 239 F.3d at 1022.

${ }_{236}$ Aimster, 334 F.3d at $654-55$.

${ }^{237}$ Grokster II, 380 F.3d at 1165-66. 


\section{A. ANALYTIC APPROACH}

The courts in the technology-centered cases emphasize detailed parsing of definitional copyright concepts, application of those concepts in the context of equally detailed explications of complex technologies, and reasoning by analogy to prior, nondigital media. It is natural that courts, when first encountering new media of fixation, first turn to the statutory language of the Copyright Act, as supplemented by judicially-created doctrines. However, some courts, like the Court in Wbite-Smith, may go no farther, relying heavily on formalistic interpretations of statutory language, or extant black letter rules, with little or no analysis of the underlying policies the law was meant to achieve. ${ }^{238}$ The courts in the technology-centered cases rely heavily on this dictionary definition approach, attempting to wedge new technologies into definitional concepts of copies, fixation, derivative works, revision, and secondary liability. ${ }^{239}$

The propensity toward the definitional approach may be exacerbated in cases involving electronic technologies because of the complexity of the systems themselves. Having just been introduced to remarkably complicated technologies, the courts must categorize them for purposes of copyright law using extraordinarily arcane terminologies whose meanings evolved in a print-based universe. The courts, in the technology-centered cases, explain in great particularity the exact functioning of the systems, as they understand them, then rely heavily on application of definitional concepts to that functionality in reaching judgment.

In Micro Star, the focus on technological dissection obscures, perhaps intentionally, the functional equivalence of the Game Genie and Nuke It..$^{240}$ In Napster, the court imports the Napster's architectural limitations into its redefinition of the knowledge requirement for contributory liability, producing a more demanding standard-actual knowledge of specific acts of infringement - than the traditional know or reason to know standard. ${ }^{241}$ In Tasini, liability equally turns on the functional characteristics of the databases. ${ }^{242}$ In all three

238 White-Smith Publ'g Co. v. Apollo Co., 209 U.S. 1 (1908).

${ }^{239}$ Trotter Hardy, addressing the issue of new subject matters, refers to this as "the dictionary definition approach." See Trotter Hardy, The Copyrightability Of Neny Works Of Authorship: "XML Schemas" as an Example, 38 HOUSTON L. REV. 855, 861 (2001). Courts frequently resort to the definitional approach when faced with new technologies. See, e.g., Teleprompter Corp. v. Columbia Broad. Sys., Inc., 415 U.S. 394, 181 U.S.P.Q. (BNA) 65 (1974) (holding that cable retransmissions of broadcast programming did not constitute public performances within the meaning of the Copyright Act); Fortnightly Corp. v. United Artists Television, Inc., 392 U.S. 390, 158 U.S.P.Q. (BNA) 1 (1968).

${ }_{240}$ See Micro Star v. Formgen, Inc., 154 F.3d 1007, 48 U.S.P.Q.2d (BNA) 1026 (9th Cir. 1998).

${ }^{241}$ See A\&M Records, Inc. v. Napster, Inc., 239 F.3d 1004, 67 U.S.P.Q.2d (BNA) 1233 (7th Cir. 2003)

${ }^{242}$ See New York Times Co. v. Tasini, 533 U.S. 483, 59 U.S.P.Q.2d (BNA) 1801 (2003). 
cases, the courts occasionally appear to be "blinded by science": so engrossed in drawing technical distinctions among systems that they ignore broader similarities and obscure or truncate discussion of significant policy issues. ${ }^{243}$

To the extent that the specifics of the technology guide the courts' ultimate judgments, one must be concerned about the completeness of their understanding. Most judges lack computer science degrees. Consequently, decisions focused too closely on system characteristics should be viewed critically. In Galoob, for example, the court fails to mention that the extra powers unleashed by the Game Genie were "Easter eggs" built in to the original games by Nintendo's designers and simply activated by the Genie's codes, a factoid that would seem to support the court's conclusion that the Genie created no derivative works. ${ }^{244}$

In Tasini, the majority frequently refers to NEXIS as a single database, ${ }^{245}$ though it is, in fact, a collection of many individual databases. Neither opinion in the case questions the presumption that the print publication is the original compilation and the electronic publications are, potentially, revisions of it. From a technical standpoint, however, one might more appropriately view the print version and the text-based electronic versions as separate, but related, spin-offs from the New York Times' pre-existing electronic files, ${ }^{246}$ just as one might view the printed Times and the web-based version of the Times as related, but separate publications (fraternal twins, not parent and child). ${ }^{247}$ The time lag between the

${ }^{243}$ In Micro Star, there is little significant discussion of the policies favoring innovation so central to the fair use analysis in Galoob. The courts in Napster and Tasini, raise policy arguments which ultimately take a back seat to the definitional arguments. While not discussed at length in this part, the opinions in Faulkner, Greenberg and Grokster are almost entirely definitional in approach. Only the court in Aimster successfully integrates necessary definitional analysis with full exploration of underlying policy issues.

244 See Steven L. Kent, The Ultimate History of Videogames 390 (2001). "Easter Eggs" are hidden surprises built into games by programmers. The first such "Egg," for example, was a secret room which was very difficult to discover. Id. at 185-89.

${ }^{245}$ See Tasini, 533 U.S. at 499-500.

${ }^{246}$ Most of the content of the New York Times was in electronic form before it was published in print. The publishers provided Lexis-Nexis with a complete copy of the same computer text files which the publishers used to produce the hard copy versions of their periodicals. The publishers added page lay out instructions to these files to produce "mechanicals" - which resembled full pages as they would appear at publication - copies of which were transmitted to printing facilities for mass production. Lexis-Nexis used the same electronic files to put the contents of each article on-line along with such information as the author's name, the publication, and page number. Tasini $v$. New York Times Co., 972 F. Supp. 804, 808, 43 U.S.P.Q.2d (BNA) 1801, 1084-05 (S.D.N.Y. 1997).

247 See THE NEW YORK TIMES ON THE WEB, at http://www.nytimes.com (last visited Apr. 3, 2005). Nowadays, the articles printed in the hard copy New York Times appear daily, in HTML format, in the Web-based version of The New York Times, complete with hyperlinks to other articles in each edition and archives of past articles. 
appearance of the print copy and the appearance of the electronic versions, ${ }^{248}$ and the implicit understanding that the print version was the flagship publication seem to be the only reasons to characterize the hard copy as an original and the electronic versions as revisions. ${ }^{249}$ Such a reading favors the majority's result, though not its reasoning, with respect to the text-based articles. On the other hand, the image-based version contained on GPO, created by digitally scanning the printed publications, ${ }^{250}$ is much more like a true revision of the original. The opinions fail to distinguish it as they should have if the justices' understanding of the technologies had been complete. Instead, both opinions fall back on generalized analogies to physical libraries and microfilm.

Again, it is a natural and time-honored judicial practice to use analogies to render complex systems in simpler, more comprehensible terms. In general, however, the analogies to prior media used by courts in the storage-and-retrieval cases fail to convince. The two opinions in Tasini differ entirely, and at length, over the conclusions to be drawn from analogies to microfilm and physical libraries. ${ }^{251}$ Midway compares videogame enhancements to speeded-up phono

248 The online versions of the New York Times and Newsday appeared within twenty-four hours after the print newspaper. Sports Illustrated appeared considerably later-within forty-five days. The time delay for NYTO was longer; NEXIS transferred magnetic tapes of the data to the CD manufacturer on a monthly basis. The agreements for data transfer had been in place for almost a decade before Tasini arose. See Tasini, 972 F. Supp. at 808.

${ }^{249}$ The entire thrust of publishing technologies for well over a decade has been to enable publication of multiple works in a variety of media from the same electronic sources, while minimizing conversions between electronic formats. See, e.g., Hardy, supra note 239, at 898-908 (describing the development of standardized markup languages identifying various parts of different kinds of documents for search purposes as well as establishing formatting of text for purposes of display or printing).

${ }^{250}$ Tasini, 972 F. Supp. at $804,808-09$.

251 The majority opinion rejected the publishers' analogy of the databases to microfilm or microfiche reproductions of periodicals, noting that microfilms usually contain miniature photographic images of entire periodicals with each article in exactly the same context in which it originally appeared. Rejecting the argument that a microfilm roll contains many publications, like a database, and that the user can focus the lens on one article at a time, the court insisted that the critical issue was whether the user initially encountered the article in context. If the articles were not perceptibly fixed within the context of the original compilation, which they clearly were not in the databases, there was no "revision." The court offered instead its own analogy to an imaginary library containing separate copies of each article which could be retrieved and physically reproduced on demand, a clear violation of the authors' rights. See Tasini, 533 U.S. at 501-02. However, Justice Stevens' dissent buys the publishers' analogy to microfilm, observing that a microfilm of an edition of the New York Times does not cease to be a revision when it is stored on the same roll of film as other editions of the Times. Inclusion on the database is no different from storage of individual issues of the newspaper in a library. As with microfilm, the fact that an individual user might view or print copies of individual articles stored on databases should be irrelevant to their status as revisions since nothing intrinsic in the databases dictates to the user how much of a particular edition 
graphs. ${ }^{252}$ The Galoob court dredges up the art reproductions pasted on tiles in the Mirage Editions case, contrasting their physical incorporation of the copyrighted works with the Game Genie's temporary substitution of data values, and comparing the Game Genie to a lens allowing buyers to view several art images simultaneously. ${ }^{253}$ In a variation on the lens analogy, the Micro Star court analogizes the Genie to a pink screen held in front of a television set, which alters the images but does not capture them in concrete form. ${ }^{254}$

These analogies fail to capture the complexity of the underlying technologies. None of the analogs involve a separate copyrightable artifact, the computer program, which functions as an intermediary facilitating production of displays. None of the analogs permit the manipulation of content, by publishers as well as users, facilitated by electronic data. Nor are the markets similar. ${ }^{255}$ The analogies to physical libraries containing physical copies do not capture the intermediate instantiation of the works in electronic files which translate the intangible work into visible displays nor can a library be characterized, as a database can, as a collective work in its own right.

The Napster and Aimster courts fare better in the use of analogy, possibly because their analogies focus not on particular media, but on legal relationships. The Napster court's analogy of the Napster system to the physical premises of a swap meet explains Napster's role vis-à-vis its subscribers. ${ }^{256}$ The Aimster court's analogy of Aimster to a stock exchange is apt because it clarifies that the goods

to view or print. Id. at 517-18. Interestingly, the Greenbery court specifically rejected this analogy, observing that microform does not require the intervention of a separate copyrightable work, a computer program, to permit viewing by the user. See Greenberg v. Nat'l Geographic Soc., 244 F.3d 1267 at 1273 n.12, 58 U.S.P.Q.2d (BNA) 1267 (11th Cir. 2001).

252 See Midway Mfg. Co. v Artic Int'l, Inc., 704 F.2d 1009, 1013, 218 U.S.P.Q. (BNA) 791, 794 (7th Cir. 1983).

${ }^{253}$ Lewis Galoob, Inc. v. Nintendo of Am., Inc., 964 F.2d 965, 968-69, 22 U.S.P.Q.2d (BNA) $1857,1859-60$ (9th Cir. 1992) (citing Mirage Editions, Inc. v. Albuquerque A.R.T. Co., 856 F.2d 1341, 8 U.S.P.Q.2d (BNA) 1171 (9th Cir. 1988) (holding that lawfully acquired art reproductions, when pasted on ceramic tiles for display, constituted derivative works)). This is a questionable precedent even for analog derivative works. See Lee v. A.R.T. Co., 125 F.3d 580, 44 U.S.P.Q.2d (BNA) 1153 (7th Cir. 1997) (rejecting Mirage on nearly identical facts and comparing mounting reproductions on tiles to framing them).

${ }^{254}$ Micro Star v. Formgen, Inc., 154 F.3d 1107, 1111 n.4, 48 U.S.P.Q.2d (BNA) 1026, 1029 n.4 (9th Cir. 1998).

255 The electronic market for news articles, for example, favors copies of individual articles in a way that the microform market does not. See Giuseppina D'Agostino, Copyright Treatment Of Freelance Work In The Digital Era, 19 SANTA ClaRA COMP. \& HIGH TECH. L.J. 37, 73, 74 (2002) (noting that the court lacks understanding of the freelance market).

${ }^{256}$ See Napster, 239 F.3d at 1022-24 (citing Fonovisa, Inc. v. Cherry Auctions, Inc., 76 F.3d 259, 37 U.S.P.Q.2d (BNA) 1590 (9th Cir. 1996)). 
are not traded on the premises. ${ }^{257}$ Well-drawn analogies might actually promote technology-neutral results by clarifying similarities and differences between systems, but the resort to analogy in the technology-centered cases is more often a source of confusion than of clarity.

Overall, the courts in the technology-centered cases rely on dictionary definitions, technical explication, and reasoning by analogy as a means of bolstering policy analyses which are relatively undeveloped or underemphasized. The Micro Star court engages in minimal policy analysis. While the Napster court expresses concern about the impact on innovation of the district court's broad injunction, ${ }^{258}$ it confines that impact by essentially reading Napster's technological limitations into the requirements for secondary liability, rather than relying on its policy-based fair use analysis. Both the majority and dissenting opinions in Tasini marshal complex technological arguments in support of an essentially simple difference of opinion over the implementation of clear congressional policy protecting the entitlements of authors against overbearing publishers. ${ }^{259}$ In the absence of significant empirical evidence, the opinions rely on convoluted readings of statutory language applied to technological particulars, producing opposing interpretations of the meaning of media neutrality as well as of the scope of the revision privilege.

The courts' reluctance to rely on policy arguments supported by empirical evidence may stem from their discomfort in the policymaking role, in light of Congress's greater institutional competence and the potential consequences to lucrative copyright markets. However, by concentrating on technological specifics, rather than overarching policies, the courts in these cases create problems both for those markets and for later courts.

\section{B. EFFECTS OF THE TECHNOLOGY-CENTERED APPROACH}

Technology-centered judgments produce several related, undesirable effects. Their narrow specificity may create uncertainty as to their applicability to existing, roughly equivalent technologies. They also generate incentives for developers to design around specific legal requirements, ultimately producing further litigation and steering innovation in directions which may prove inefficient or otherwise suboptimal.

${ }^{257}$ See In re Aimster Copyright Litigation, 334 F.3d 643, 647, 67 U.S.P.Q.2d (BNA) 1233, 1236 (7th Cir. 2003).

258 See Napster, 239 F.3d at 1021.

${ }^{259}$ The majority believes that authors, not publishers, ought to profit from new electronic markets. Tasini, 533 U.S. at 497 . The dissent believes that both authors' interests and the public interest in dissemination will be better served by allowing publishers to redistribute the contents of their collections in electronic formats. Id. at 520-24. 
Judicial over-reliance on the specifics of particular technologies produces uncertainty as to which technological variations will be deemed infringing and which will not. ${ }^{260}$ For example, since computer programs utilize different kinds of memory and organize memory in different ways, it is difficult to predict where a particular videogame system may fall in the Galoob-Micro Star spectrum. ${ }^{261}$ The majority opinion in Tasini offers little guidance for future developers of database compilations. Napster's technology-driven result essentially guaranteed future litigation over systems which avoided the central server architecture. The current path of that litigation may, ultimately, force the legislative intervention which media neutrality was meant to avoid.

Napsterclearly illustrates that technology-centered judgments invite innovators to design around the specific elements found to infringe. The practice is reminiscent of the practice of designing around the claims of a patent. Here, however, inventors are designing around the requirements of the copyright law itself as interpreted through application to certain technologies. Such practices breed disrespect for the law and tend to produce further, expensive litigation as courts must pass judgment on each new technological variant.

In addition to encouraging further litigation, technology-centered judgments may forcibly steer development toward less efficient technologies than those the market would develop if left to its own devices. For example, fully contextual image-based or textual databases can be produced, but are likely to be more expensive than text-based alternatives. Many database users would undoubtedly find such a presentation inconvenient to download or use. ${ }^{262}$ While decentralized file sharing systems have advanced considerably, centralized services like those ruled illegal in Napster and Aimster may be more efficient. ${ }^{203}$

${ }^{260}$ One might equally argue, of course, that Sony-based analyses produce unpredictable results.

261 See, e.g., Edward G. Black \& Michael H. Page, Add-On Infringements: When Computer Add-Ons and Peripherals Should (and Should Not) Be Considered Infringing Derivative Works Under Lewis Galoob Toys, Inc. v. Nintendo of America, Inc., and Otber Recent Decisions, 15 HASTINGS COMM. \& ENT. L.J. 615, 625-26 (1993).

${ }^{262}$ See Laurie A. Santelli, Note, New Battles Between Freelance Authors And Publishers In The Aftermath Of Tasini v. New York Times, 7 J.L. \& POL'Y 253, 295 (1998).

${ }^{263} \mathrm{Wu}$, supra note 55 , at 717.

The technical study of P2P design shows that designing a P2P file sharing network to avoid copyright requires important deviations from the optimal design for speed, control, and usability. The programmers of a copyrightresistant P2P network must balance an interest in avoiding legal liability against the competing interests of ensuring performance on a mass scale, maintaining system stability, and fostering network trust. These matters all require control over the network, while a pure peer design eliminates control as much as possible. 
Judge Posner's implication in Aimster that developers might be required to alter their designs in order to avoid vicarious liability would actually worsen the adverse effect of judicial intervention by directly involving courts in technological determinations best left to developers. ${ }^{264}$ While uncertainty as to the scope of copyright protection may reduce incentives for copyright owners to release their works in digital formats, the greater adverse impact may be on incentives for technology providers to push innovation in directions which are efficient and economically and technologically sound. Judicial steering of technology, combined with the unpredictability of future legal results, may chill innovation, which Sony sought to avoid by adopting a less technology-focused, more policydriven analysis.

From the standpoint of media neutral decisionmaking, two aspects of Sony are notable: that it employed a policy-based analysis centered on balancing the need for copyright incentives against the public interest in innovation, and that it was relatively indifferent to the specifics of videotape recorder technology, focusing on what the videotape recorder did, not on how it did it. ${ }^{265}$ Sony offers some guidance in crafting a more media-neutral approach which alleviates some of the problems associated with technology-centered decisionmaking. If courts, in the interest of applying copyright law in a media neutral manner to protect the legitimate rights of copyright owners, must effectively prohibit some technologies or certain uses of them, a more comprehensive method of analysis would assure that the courts take into account the broader policy concerns and market impacts which should drive their decisionmaking.

\section{MEDIA-NEUTRAL, POLICY-INFORMED AdJUDICATION}

Numerous commentators have analyzed the challenges to copyright posed by electronic media and have suggested various strategies for revising copyright law to meet those challenges. Suggested cures include recasting copyright to protect rights of access ${ }^{266}$ or of commercial exploitation ${ }^{267}$ and incorporation of more

${ }^{264}$ The appellants in Grmester II urged the Ninth Circuit to adopt an alternative design rule in that case. As an opposing amicus brief pointed out, such a rule would embroil the courts in technological decisionmaking, allow copyright owners to control technological development, and adversely impact innovation. See Brief of 40 Amici Curiae Intellectual Property and Technology Law Professors, at 17-19, Grokster II, 380 F.3d 1154 (9th Cir. 2001) (No. 03-55894, 03-55901), available at http://www. eff.org/IP/P2P/MGM_v_Grokster/\#nc-defendant-amicus.

${ }^{265}$ The court describes the workings of the VCR in reasonable detail, but does not rely on technological detail in reaching its judgment. Sony Corp. of Am. v. Universal City Studios, 464 U.S. 417, 422-23, 220 U.S.P.Q. (BNA) 665, 670 (1984).

266 See, e.g., Ginsburg, supra note 36 , at 3.

267 See, e.g., LITMAN, supra note 104, at 180. 
explicit recognition of user's rights. ${ }^{268}$ No major legislative overhaul appears imminent, however, and courts must adjust existing copyright law as best they can to fit new technologies. The principle of media neutrality was adopted by Congress for that purpose and judicial adherence to media-neutral analysis should improve copyright's flexibility in the near term. The following proposals for assuring media neutrality may be viewed as a set of stopgap measures to keep copyright workable in the interim before copyright law's next legislative transformation, if one should occur.

The results in the technology-centered cases suggest that the courts became so enamored of technological distinctions that they failed to accord similar treatment to equivalent technologies, pronounce doctrinal rules of general applicability across technologies, or give appropriate weight to broader policy concerns. Three rules-of-thumb should keep courts on a media-neutral keel. First, where statutory guidance is lacking or ambiguous, courts should afford functionally equivalent technologies, whether analog or digital, similar treatment under copyright law unless they can articulate a compelling doctrinal or policy reason that dictates otherwise. Second, courts interpreting copyright doctrines in light of new technologies should avoid emphasis on the details of particular technological systems and interpret copyright's core concepts in terms applicable across technologies. Third, courts should give more weight to broader policy considerations such as fairness, incentives, and innovation, and should consider empirical evidence relevant to those policy determinations. While judgments should be technology-sensitive, they should not be technology-driven; technological detail may matter, but should not, standing alone, be outcome-determinative.

\section{A. THE GUIDELINES}

Media neutrality implies that, in the absence of clear statutory guidance, courts make at least rough judgments of equivalence not only between analog and digital technologies, but also between different digital technologies. Rather than relying on analogies to lenses or pink screens, courts should focus on the functional equivalence of works embodied and delivered in different media. Very loosely adopting a principle from patent law, this approach might be described as a sort of inverted function-way-result test: if two technologies perform the same function or produce the same result, even though they do so in different ways, courts should accord them similar treatment under copyright law unless an overriding, well-articulated doctrine or policy concern dictates otherwise.

${ }^{268}$ See, e.g., Liu, supra note 41, at 1337-60. 
In analog to digital transformations of content, media neutrality requires that the essential addition of functional software simply to enable communication of the content should not, in itself, be viewed as creation of a new, possibly infringing, derivative or collective work. Derivative and collective works should require some additional variation from the original. Content merely enabled by software should be seen as the functional equivalent of an analog copy, if the work is captured in sufficiently stable form. Different digital storage and retrieval technologies that equally serve to capture copies of content should receive like treatment. Media neutrality also suggests that uploading or downloading a work over a network should be treated as the functional equivalent of distribution of physical copies, again provided that the work takes relatively stable form at the end point of the transaction. ${ }^{269}$

Some analysis of system functionality is unavoidable in technology-intensive cases and courts would be well-advised to employ neutral technical experts, provided the courts can resist the impulse to rely entirely on technological detail as the basis for judgment. The district court in Napster employed such an expert. ${ }^{270}$ Courts should have enough basic understanding of the technology to make well-informed choices when they seek to compare equivalent technologies. ${ }^{271}$ Interested parties in litigation are unlikely to provide complete, unbiased expertise, not only because they act as advocates, but also because of information asymmetries. In some instances, one side may possess expertise that the other does not. ${ }^{272}$

269 This conclusion does not necessarily mandate that temporary RAM copies should be viewed as functional equivalents of permanent copies, though the courts to date have certainly taken that view. While the RAM copy doctrine clearly has adverse consequences unforeseen by Congress, neither Congress nor the courts have altered it legislatively or judicially in the ten years that have passed since the court in MAI Systems Corp. v. Peak Computer, Inc., 991 F.2d 511, 518, 26 U.S.P.Q.2d (BNA) 1458 (9th Cir. 1993), formulated it. At this point, resistance may be a less effective strategy (i.e., "futile") than damage control through, for example, reliance on the public display right, implied license theories, or personal use privileges.

${ }^{270} S_{e e}$ A\&M Records, Inc., v. Napster, Inc., 284 F.3d 1091, 1097, 62 U.S.P.Q.2d (BNA) 1221 (upholding the lower court's use of a technical advisor against Napster's claim that the court improperly delegated its judicial authority).

${ }^{271}$ Japan's Supreme Court recently announced appointment of a large roster of intellectual property experts to assist its judges in navigating the complexities of both the law and the technology. See 100 Intellectual Property Experts to Assist Judges, DAILY YOMURI, Aug. 28, 2003 (copy on file with author). As intellectual property cases grow ever more complex, such a resource could be invaluable in this country as well.

${ }^{272}$ The publishers in Tasini, 523 U.S. 483, for example, were surely aware that print and electronic products could be viewed as spinoffs from the same electronic sources, but it did not behoove them to argue the point. The freelancers and their attorneys were unlikely to understand the processes employed by print and electronic publishers. 
To the extent that the copyright balance of incentives and access has been appropriately set for a pre-existing technology, similar treatment of functional equivalents should maintain that balance. A focus on functional equivalency might also direct the courts' search for apt analogies into a more fruitful path. Parties may, and likely will, differ over the appropriate equivalent for a given technology and courts may still misunderstand the true nature of new technologies. ${ }^{273}$ Nonetheless, by directing their inquiry towards general functional equivalence and away from dissection of system specifics, courts may avoid pinning their judgments on short-lived technological detail rather than lasting principles governing rights and liabilities.

A judicial predisposition to treat functional equivalents similarly in the absence of guidance from Congress would not prevent Congress from mandating otherwise in the exercise of its greater institutional ability to weigh the full spectrum of competing interests in the setting of copyright policy. Congress might well choose, as it has in the past, to treat equivalent technologies differently and courts are, of course, bound by that determination. For example, in cases involving video rentals to hotel guests, courts distinguished between differently configured in-room video delivery systems where Congress established a basis for differential treatment in the statutory definition of public performance ${ }^{274}$ and through clear references to hotel rentals in the legislative history. ${ }^{275}$

${ }^{273}$ See, for example, Teleprompter Corp. v. Columbia Broadcasting System, Inc., 415 U.S. 394, 191 U.S.P.Q. (BNA) 65 (1974), in which the Supreme Court found that cable television companies retransmitting broadcast signals performed the equivalent of viewer functions (receiving signals) rather than broadcaster functions, a finding clearly belied by the subsequent development of cable television systems as competitors of broadcast television.

${ }^{274}$ See 17 U.S.C. $\$ 101$ (2002) (defining the phrase "to display or perform a work 'publicly" "). Public performances, as defined, include either performances in a public place or transmissions to such a place or to the public.

${ }^{275}$ Cf. Columbia Pictures, Inc. v. Profl Real Estate Investors, Inc., 866 F.2d 278, 9 U.S.P.Q. (BNA) 1653 (9th Cir. 1989) (finding no violation of movie studios' public performance right where hotel provided equipment in each room and rented video discs to individual guests for use in those rooms); OnCommand Video Corp. v. Columbia Pictures Indus., 777 F. Supp. 787, 21 U.S.P.Q.2d (BNA) 1545 (N.D. Cal. 1991) (finding violation of the "transmit" portion of the statute where bank of VCRs were centrally located in hotel equipment room and movies were transmitted to individual rooms upon request by guests). In both cases, the courts found that rented hotel rooms were not public places within the meaning of the statute. See Profl Real Estate, 866 F.2d at 281; OnCommand, 777 F. Supp. at 789. However, the statutory definition of the term "transmit" and legislative history indicating that Congress specifically intended the transmission provision to apply to hotel rooms made clear, in the opinion of both courts, that the OnCommand system indeed transmitted a performance while the Real Estate Investors' system did not. See Prof'/ Real Estate, 866 F.2d at 282, n.7; OnCommond, 777 F. Supp. at 789-90. A functional equivalence approach might in fact produce the same results, on grounds that the Real Estate Investors' system is equivalent to renting a VCR and a copy of a movie from a video rental store, while the OnCommand system is the equivalent of 
Additionally, technological distinctions continue to carry some analytical weight with respect to the primary or secondary nature of the defendant's potential liability. A defendant like MP3.com which, as a part of its service, actively reproduced its own copies of works would remain subject to liability as a direct infringer, ${ }^{276}$ while an enabler like Napster would remain subject to the standards for contributory or vicarious liability. To some extent, the determination of functional equivalence might automatically encompass these distinctions. ${ }^{277}$

In some cases, as in Midway, ${ }^{278}$ there may be no pre-existing functional equivalent to a new digital technology, or at least none on which a prior court has passed judgment. In that event, courts must apply copyright principles in unfamiliar contexts. They should resist the impulse to rewrite those principles in terms of technology specifics which are likely to change over time. One would not expect a court to alter the established rules for contributory liability, for example, by revising them to fit the technology of a particular case as the court did in Napster. To the extent that courts adapt principles from related fields, or establish new doctrine, they should be careful to formulate the doctrine in technology-neutral terms. In Sony, for example, the court states the staple article of commerce doctrine, borrowed from patent law, in terms which apply across technologies. ${ }^{279}$ For cases arising after the case of first impression, media neutrality indicates that different digital products which perform the same function should receive similar legal treatment, provided that the court of first impression has correctly interpreted the applicable legal principles and weighed the relevant policy issues.

Adherence to the black letter law should be leavened by consideration of broader policy goals-not only those underlying the Copyright Act but also those favoring technological innovation which are frequently at issue in cases involving extension of copyright law to new technologies. Courts in technology-intensive cases should be less hesitant to tackle policy issues head on, rather than by indirection, and should marshal empirical support for policy-guided decisionmaking. Sony points in this direction, with its discussions of the broadcast and VCR markets and its balancing of copyright incentives against innovation in

a broadcast. It should be noted that, unlike the electronic systems discussed herein, neither of these systems involved reproduction or distribution of a copy.

${ }^{276}$ See UMG Recordings, Inc. v. MP3.com, Inc., 92 F. Supp. 2d 349, 54 U.S.P.Q.2d (BNA) 1668 (S.D.N.Y. 2000).

${ }^{277}$ With respect to MP3.com, for example, the court's determination that the service's activities were the equivalent of copying, rather than the equivalent of storing music in a locker, settled its direct liability. Id. at 350 .

${ }^{278}$ Midway Mfg. Co. v. Artic Int'l, Inc., 704 F.2d 1009, 218 U.S.P.Q. (BNA) 791 (7th Cir. 1983).

279 Sony Corp. of Am. v. Universal City Studios, 464 U.S. 417, 220 U.S.P.Q. (BNA) 665 (1984). 
other markets. ${ }^{280}$ Sony deploys a policy of deference to the legislature where copyright expansion might endanger unrelated markets, but unlike White-Smith, bases that deference not on formalistic interpretation of statutory definitions, but on a pragmatic analysis of the implicated policies and available empirical evidence. $^{281}$

Courts employing the Sony approach might be expected to explore the economic impact of copyright extension on the markets involved in each case, seeking to avoid judicial creation of legal rules that would impose negative externalities on one industry by protecting another. The importance of protecting innovation in new and developing markets suggests, moreover, that such concerns be weighed with respect to all claims of secondary liability, whether contributory or vicarious, notwithstanding the Ninth Circuit's attempt to limit Sony's influence to contributory claims. The principle of media neutrality empowers courts to expand old rules to cover new technologies. Sony counsels caution in judicial extension of copyright protection where unrelated markets are implicated, drawing a line beyond which courts should not go without legislative guidance based on potential impact on innovation. The legislative forum remains available for resolution of competing interests in such cases.

The three proposed guidelines are simple and, one would have thought, obvious, had not the courts in the technology-centered cases so signally failed to employ them. I do not suggest that courts should abandon due regard for statutory language or judicial precedent, or even entirely ignore distinctions between technological systems, but rather that the application of text to technology should be accompanied by full and fair review of policy concerns and consideration of likely market impacts. Judgments should not hinge exclusively, or even primarily, on fine distinctions among the mechanics of different delivery systems. Adherence to the proposed guidelines might produce more satisfactory rationales in Micro Star, Tasini, and Napster.

\section{B. RETHINKING THE CASES}

The decisions in the technology-centered cases may be reconstructed using the balanced, policy-informed analysis proposed above. In Micro Star, such reconstruction not only alters the form of the analysis and the nature of liability, but might actually produce a different outcome. In Tasini and Napster, the

${ }^{280}$ The Sony majority engages in a fairly lengthy discussion of consumer surveys regarding the purposes of home taping, mixed opinions in the broadcast industry as to whether home taping was advantageous or detrimental to content owners, testimony concerning authorized home taping for educational and religious purposes, and the like. Id. at 423-24.

${ }^{281}$ Id. at 431. 
guidelines, in combination with clearer understanding of the technology and alternative theories of liability, would not change the result but would provide a more comprehensive analysis.

1. Micro Star. The games cases represent a complete cycle of a case of first impression, followed by a doctrinal reinterpretation informed by policy analysis, followed by a technology-centered alteration lacking a doctrinal or policy base. Midway was the case of first impression. Somewhat hamstrung by the plaintiffs failure to copyright its code as well as its audiovisual displays, the court did its best to apply derivative works principles as informed by its policy concerns with market harm, hence disincentives to creators, and flexibility of interpretation. While the decision in Galoob departs from Midway, it does so based on its generalized conclusion that the derivative works doctrine requires some physical embodiment, an issue not addressed by the Midway court. In its fair use dicta, the Galoob court also provides a policy analysis supporting its rejection of the Seventh Circuit precedent.

Micro Star, on the other hand, applies the same legal principles to a functionally equivalent technology, but relies on technical differences in the systems to distinguish Galoob. While the Game Genie and Nuke Ils MAP files operate in different ways, both are essentially triggers kicking off game enhancements. Under the functional equivalency guideline, they should be treated similarly unless the court can come up with a sound doctrinal or policy reason for doing otherwise.

The court might, for example, have reassessed its interpretation of derivative works infringement as requiring a concrete embodiment rather than twisting the doctrine to encompass mere description. No other circuit has adopted the embodiment standard; if the Ninth Circuit had abandoned it, Galoob would no longer be controlling. Unless the court shifted its doctrinal stance, however, media neutrality would indicate that Galoob should preclude any finding of direct infringement because the MAP files did not embody Formgen's protected material.

Interestingly, the Micro Star court might have applied the RAM copy doctrine, which did not exist at the time Galoob was decided, ${ }^{282}$ to establish infringing embodiment (indeed full fixation) not in the MAP files, but in the displays produced on users' screens and necessarily captured in RAM. Using that approach, the court should have analyzed the case as involving contributory, rather than direct, liability. The court might well have found that Micro Star knowingly enabled end users to recreate altered game displays. It should then

${ }^{282}$ The court adopted the RAM copy doctrine in MAI Sys., 991 F.2d at 518. 
have determined whether Micro Star was protected by fair use and the staple article of commerce doctrine.

The different nature of the markets in Galoob and Micro Star, and clear freeriding by Micro Star, might tip the analysis in Formgen's favor were it not for the existence of the user license, which weighs in favor of a result that the court clearly wished to avoid. ${ }^{283}$ Though the court gave short shrift to the licensing and abandonment arguments, Formgen surely should have foreseen the possibility that an enterprising third party, not bound by Formgen's license, would make use of the new levels; Formgen must have weighed that risk against the value gained from broader dissemination and user satisfaction and assumed the risk. At a minimum, the license should affect the fair use analysis by negating any expectation by Formgen that it could exercise market rights in the user-created levels. More broadly, the license may constitute abandonment of any claim to rights in the new levels. Formgen should go home empty-handed to reconsider its marketing strategy.

2. Tasini. There are several alternative analyses which might have produced more satisfactory rationales in Tasini. A better understanding of the technologies involved and a clearer focus on the different products and the rights infringed, balanced by a more comprehensive statement of the policy underlying section 201 , would produce stronger support for the majority's result.

In the simplest approach to the case, the court should, as suggested above, ${ }^{284}$ view the print publication and the files provided to NEXIS and NYTO as different spinoffs from the same electronic source. Consequently, NEXIS and NY'TO cannot conceivably be viewed as revisions of the print publications, even under a dictionary definition approach. The image-based GPO, on the other hand, is a subsequent re-use of the print publications which must be analyzed separately, but which appears to constitute a new anthology, not a revision. Even if one rejects this analysis and assumes that NEXIS and NYTO are successors to the print publication, the proposed guidelines produce the same results.

NEXIS provides two different products: access to databases for research purposes and downloads for later use. Clearly the functional equivalent of a copy of the print compilations is produced in the database itself regardless of how it is stored. Reasonable minds might differ over whether such inclusion in the database creates a new collective work. However, a focus on distribution suggests that, at a minimum, NEXIS actively distributed the functional equivalent of copies of the individual articles, directly violating the authors' distribution right. ${ }^{285}$ Users downloading individual articles also created the functional equivalents of

283 See Micro Star, 154 F.3d at 1113-14.

284 See infra Part III.B.

${ }^{285} S_{e e}$ Gordon, supra note 38 , at 475-76, 488-89. 
copies, violating the reproduction right, for which the publishers would be contributorily responsible, making the Sony defense relevant, though a finding of direct infringement of the distribution right would render such analysis superfluous.

The NYTO and GPO CDs, on the other hand, were distributed as compilations of original issues, requiring a more extensive inquiry into whether they were functional equivalents of revisions or new collective works. Congress, in the legislative history, indicated that a

publishing company could reprint a contribution from one issue in a later issue of its magazine, and could reprint an article from a 1980 edition of an encyclopedia in a 1990 revision of it, but publishers could not revise the contribution itself or include it in a new anthology or an entirely different magazine or other collective work. $^{280}$

Since GPO included publications other than those taken from the New York Times, it clearly constitutes a new anthology and, hence, a new collective work under section 201(c). NYTO, which accumulated only issues of the New York Times, presents a more difficult case. The Faulkner court read the "entirely different" language to indicate that a collective work which is merely somewhat different from the original is privileged and relies on Tasini dictum regarding microforms to conclude that accumulations of issues of the same periodical are permissible. ${ }^{287}$ One can as easily read the passage, standing alone, to indicate that an accumulation of issues, like NYTO, is a new anthology collecting multiple, previous compilations (the individual issues). In the absence of clear direction from Congress, the court should have resolved the question by emphasizing the policy underlying section 201 (c).

The legislative history of section 201(c) clearly supports the majority's interpretation of Congress's intent to equalize the balance of power between individual authors and publishers. ${ }^{288}$ The overriding policy issue reflected in that history is fairness in the allocation of incentives for creation, not, as Justice Stevens argues, efficiency of dissemination. The majority offers sufficient empirical evidence to support that policy analysis, based on the impact on the

${ }^{286}$ See H.R. REP. No. 94-1476, at 122-23 (1976).

${ }^{287}$ Faulkner v. Nat'l Geographic Soc'y, 294 F. Supp. 2d 523, 540-41, 69 U.S.P.Q.2d (BNA) 1370, 1384 (S.D.N.Y. 2003).

${ }^{288}$ Wendy Gordon observes: "Given what Congress intended when enacting the provision, it seems absurd to contend that publishers who pay for print rights should also presumptively have free rein to sell mass licenses to electronic media." Gordon, supra note 38, at 484-85. 
authors' markets for new anthologies. Had the court emphasized this argument and clarified the question whether accumulation of multiple issues was permissible, it might have avoided the result in Faulkner, which undercuts the policy protecting authors. Indeed, the combination of Tasini, Faulkner, and the publishers' new practice of requiring that freelancers license all conceivable rights as a prerequisite to publication, ${ }^{289}$ suggests that if Congress retains any interest in protecting powerless freelancers against overreaching publishers, it must devise a better mechanism than section 201(c).

The court would have done well to pursue an alternative argument, urged by the Register of Copyrights, that the critical right infringed in Tasini was the right of public display. The Register argued "vigorously" that the display of individual articles to users violated the authors' right to public display and that since section 201(c) provides publishers no display privilege, the defendants should be held liable. ${ }^{290}$ This approach, had the court taken it, might have avoided the difficulty of defining copies and revisions, and their functional equivalents, in the electronic context. When combined with the policy analysis, it would also have provided a more satisfactory rationale for the result.

3. Napster. Re-imagining Napster is fairly simple since Judge Posner came close to doing so in Aimster. ${ }^{291}$ The functional equivalence guideline indicates that peer-to-peer systems, whether they are centralized or decentralized, enable the same activity-sharing of copyrighted works among users-and should be accorded similar treatment under copyright law absent an overriding doctrinal or policy concern. The focus on generalized rules precludes the rewriting of the rules of secondary liability to fit Napster's particular architecture. Under the traditional test for contributory liability, Napster clearly met both the knowledge and material contribution requirements. The staple article of commerce doctrine, properly construed, would then require that the court determine whether Napster had substantial noninfringing uses. The court could simply have emphasized its fair use analysis, where the lack of strong empirical evidence for noninfringing uses, the continuing relationship between Napster and its users, and the unified

${ }^{289}$ See Maureen A. O'Rourke, Bargaining in the Shadow of Copynight Law After Tasini, 53 CASE W. RES. L. REV. 605 (2003).

${ }^{290}$ New York Times Co. v. Tasini, 533 U.S. 483, 498 n.8, 59 U.S.P.Q.2d (BNA) 1801, 1812 n.8 (2001).

${ }^{291}$ Cf. In re Aimster, 334 F.3d 643, 67 U.S.P.Q.2d (BNA) 1233 (7th Cir. 2003); A\&M Records, Inc. v. Napster, Inc., 239 F.3d 1004, 57 U.S.P.Q.2d (BNA) 1729 (9th Cir.) (2001). 
front presented by the music industry ${ }^{292}$ would have produced the same result without reliance on Napster's architecture.

The court in Aimster uses the same techniques used in the technology-centered cases-technical explication, reasoning by analogy, application of copyright concepts to the facts at hand-without losing sight of overriding policy concerns. ${ }^{293}$ The court recognizes Napster as a functional equivalent of Aimster and departs from Napster not on the basis of system architecture, but on the fundamental issue of interpretation of the requirements for secondary liability. ${ }^{294}$ The court's interpretation of the staple article of commerce doctrine to require empirical evidence of the magnitude of infringing and noninfringing uses and a balancing by the court of the relative importance of those uses sets a standard which may exceed that established by Sony. ${ }^{295}$ The suggestion that developers might be required to redesign products to avoid vicarious liability is certainly illconceived. Nonetheless, viewed as a method of analysis, Judge Posner's approach puts the court where it should be-judging the parties' competing interests based on application of generalized copyright principles to the facts adduced with due regard for significant policy concerns. Though Aimster resulted in the shut-down of a particular file sharing service, it left the door open for the next "killer app" for peer-to-peer to establish substantial noninfringing uses immunizing it from liability under Sony. While the future of peer-to-peer may be no more predictable under such an analysis, it depends on establishment of new, noninfringing markets, rather than on technological redesign to avoid legal barriers.

Applying a more media-neutral approach in the three cases above, the respective courts might well have placed emphasis on different aspects of the analysis, but in no case would the particulars of system architecture have been the decisive element in decisionmaking. While judicial understanding of the technology is certainly essential, the policy favoring media neutrality counsels against giving the technology center stage in infringement determinations.

292 The Sony court relied fairly heavily on the disagreement within the broadcast community over the costs and benefits of home taping and on the fact that Sony simply sold the VCR, thereafter having no control over its users. See generally Sony, 464 U.S. 417. In Napster, while artists were divided, the corporate owners of the large majority of the copyrights involved spoke with a single voice. Napster, 239 F.3d 1004 . Napster also maintained a continuing relationship with its users, which was essential to their activities. Id.

293 See generally Aimster, 343 F.3d 643.

${ }^{294}$ Id.

295 See Sony, 464 U.S. 417. 


\section{CONCLUSION}

The 1976 revision of the Copyright Act incorporated the doctrine of media neutrality as a hedge against foreseeable challenges to traditional copyright principles and policies by electronic media. The rapid pace of modern technological change simply precludes legislative resolution of every conflict between copyright owners and the developers and users of new technologies of copying and dissemination. Congress rightly expected the courts to take an important role in resolving those conflicts. I have proposed a fairly expansive reading of media neutrality in copyright as encouraging judicial indifference to fine technical distinctions among systems which store and deliver copyrighted content. I have also suggested that the Sony court's reservations about judicial expansion of copyright and its policy-based analytic framework establish an important limiting principle that balances copyright policies against innovation policies.

The media-neutral, policy-sensitive analytic approach suggested above is anything but revolutionary; it is more in the nature of a reminder to courts to adhere to Congress' clearly stated intent that copyright principles and results should not be technology-dependent, unless Congress clearly indicates otherwise. The proposal encourages a shift in judicial emphasis away from the mechanics of information storage and delivery towards principles of general applicability and policy-based analysis employing empirical tools. Judicial deliberations should, insofar as possible, encompass the broad view as well as the narrow definition and distribute copyright protection evenhandedly among similar technologies. Application of that approach to the technology-driven cases discussed above would have produced more readily transportable interpretations of the relevant law and reduced the impetus to design around the strictures of copyright law.

Courts employing this analysis may yet come up against some walls which they rightly refuse to surmount without congressional guidance. In that event, the courts' expanded rationale might offer a better guide for legislative action should Congress choose to act. Electronic technologies, and accompanying changes in cultural attitudes toward copying, ${ }^{296}$ may ultimately stretch copyright to its breaking point and require an overhaul of the statute. Some have suggested that such a revision might require the application of different rules to electronic and analog works. ${ }^{297}$ Until that time, judicial adherence to media neutral, policysensitive analysis should provide existing copyright law with the interim flexibility to adapt to rapidly changing technologies.

${ }^{296}$ See, e.g., John Leland, Beyond File sharing, a Nation of Copiers, N.Y. TIMES ON THE WEB, Sept. 14, 2003, abstract and link to archive, available at http://query.nytimes.com/gst/abstract.html?res $=\mathrm{FB} 0$ A16FD3A5F0C778DDDA00894DB404482 (last visited Jan. 28, 2005).

${ }^{297}$ See, e.g., David G. Post, His Napster's Voice, 20 TEMPLE EnVTL. L. \& TECH.J. 35, $41-48$ (2001). 
Journal of Intellectual Property Law, Vol. 12, Iss. 2 [2005], Art. 3 